This item was submitted to Loughborough's Research Repository by the author.

Items in Figshare are protected by copyright, with all rights reserved, unless otherwise indicated.

\title{
An investigation of using various diesel-type fuels in homogeneous charge compression ignition engines and their effects on operational and controlling issues
}

\section{PLEASE CITE THE PUBLISHED VERSION}

\section{PUBLISHER}

(C) IMechE / Professional Engineering Publishing

\section{VERSION}

VoR (Version of Record)

LICENCE

CC BY-NC-ND 4.0

\section{REPOSITORY RECORD}

Milovanovic, Nesa, Rui Chen, R. Dowden, and J.W.G. Turner. 2009. "An Investigation of Using Various Dieseltype Fuels in Homogeneous Charge Compression Ignition Engines and Their Effects on Operational and Controlling Issues". figshare. https://hdl.handle.net/2134/4500. 
This item was submitted to Loughborough's Institutional Repository (https://dspace.lboro.ac.uk/) by the author and is made available under the following Creative Commons Licence conditions.

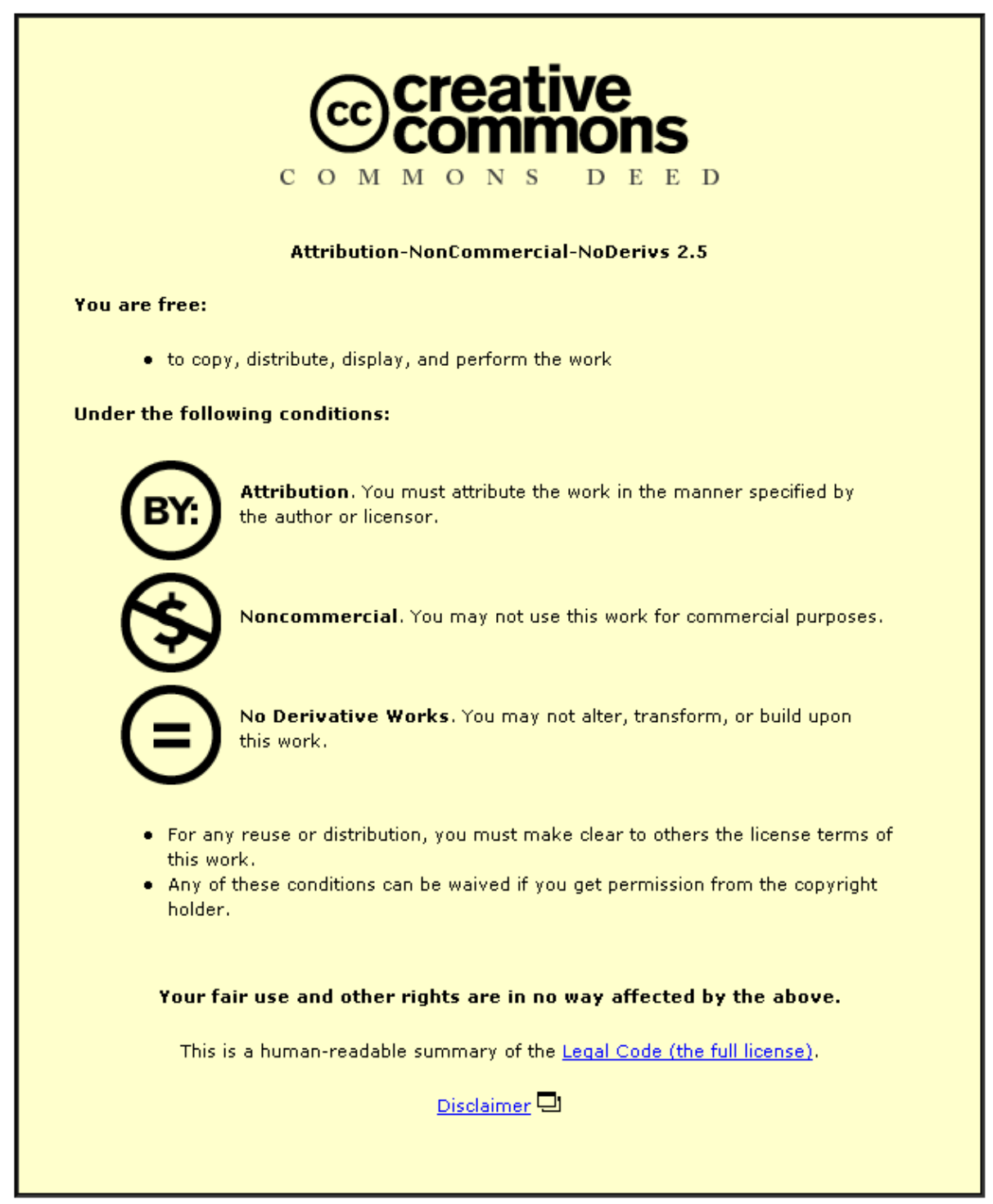

For the full text of this licence, please go to: http://creativecommons.org/licenses/by-nc-nd/2.5/ 


\section{An investigation of using various diesel-type fuels in homogeneous charge compression ignition engines and their effects on operational and controlling issues}

\author{
N Milovanovic and $\mathbf{R}$ Chen \\ Aeronautical and Automotive Department, \\ Loughborough University, Loughborough, \\ Leicestershire, UK
}

\section{R Dowden}

School of Automotive Engineering,

Swansea Institute of Higher Education,

Swansea, Wales, UK

\section{J Turner \\ Powertrain Research Department, Lotus \\ Engineering, Hethel, Norfolk, UK}

Accepted 15 January 2004
The results indicate that the use of bio-diesel fuels will result in lower sensitivity of ignition timing to changes in operational parameters and in a better control of the ignition process when compared with the use of n-heptane and dimethyl ether.

Key words: HCCI, bio-diesel, dimethyl ether, n-heptane, internal exhaust gas recirculation, fully variable valve timing

\section{Introduction}

The homogeneous charge compression ignition (HCCI) combustion is a process that combines features of spark-ignited and compression-ignited combustion processes. In an HCCI engine, the fuel and air are premixed to create a homogeneous charge, as occurs in spark ignition (SI) combustion. The charge is then ignited by the compression as in compression ignition (CI) combustion. Unlike conventional SI and CI engines, an HCCI engine has no need for 
a centralized combustion initiation. Therefore, the entire charge gives a parallel energy release as the whole mixture burns simultaneously without obvious flame propagation.

The HCCI engine has the potential to deliver high efficiency and very low $\mathrm{NO}_{x}$ and particulate matter emissions. Low cost is realized as no high-pressure injection system is required. The disadvantages of the HCCI engine are relatively high hydrocarbon and carbon monoxide emissions*, high peak pressures and rates of heat releases, reduced engine operating range and power and difficulties in starting and controlling the engine. Some of these disadvantages may be reduced by operating the HCCI engine in 'hybrid mode', where the engine operates in HCCI mode at low power and in SI mode [6] or diesel model [7] at high power.

Unsolved problems that currently keep the HCCI from commercial viability are the difficulty in controlling the engine over the required operational load/speed range, together with the higher hydrocarbon emissions. The problem with controlling the HCCI engine operation is the difficulty in ensuring that the start of ignition occurs in the vicinity of top dead centre (TDC) and that the heat release rate over the operational range is controlled. In the HCCI engine, there are no direct methods to control ignition timing and the heat release rate because the combustion process is governed predominantly by the chemical kinetics of the air/fuel mixture. A number of different methods that have the potential to control the start of autoignition and the heat release rate of the HCCI combustion, together with their effectiveness and practical feasibility, have been discussed in reference [8].

The aim of this paper is to analyse the possibility of using different types of diesel fuels in the HCCI engine and to find the most suitable one for operational and control issues. The following diesel fuels are investigated: $n$-heptane, dimethyl ether and bio-diesel fuels (methyl butanoate and methyl formate).

$n$-Heptane is a primary reference fuel that has a cetane number $(\mathrm{CN})$ very close to that of diesel fuel (CN 56). Dimethyl ether (DME) represents a clean alternative fuel for a diesel engine due to its high centane number (CN 60-70), smokeless combustion properties and favourable ignition properties $[9,10]$.

* Relatively high carbon monoxide emissions have been observed in HCCI engines fuelled with diesel fuels at low load operation conditions $(\phi<0.2)[1,2]$. On the other hand, in HCCI engines fuelled with gasoline fuel and operated with internal gas recirculation an increase in the carbon monoxide emission, at low load, has not been observed [3-5].
Bio-diesel fuels can be derived from vegetable oils and animal fats. These fuels offer benefits of low sulphur content and the possibility of renewal in comparison to common diesel fuels. Typical biodiesel fuels consist of mixtures of saturated and unsaturated methyl esters (methyl butanoate, methyl formate, methyl oleate, methyl palmitate, etc.) [11]. Methyl butanoate (MB) is chosen as a surrogate for heavy bio-diesel fuels, while methyl formate (MF) is chosen for light bio-diesel fuels [12]. The reason for the selection of MB is its essential chemical structure features like those in heavy biodiesel fuels, namely the $\mathrm{RC}(=\mathrm{O}) \mathrm{OCH}_{3}$ structure (where $\mathrm{R}$ is an alkyl or alkenyl radical). Although MB does not have the high molecular weight of a bio-diesel fuel, it is large enough to allow fast $\mathrm{RO}_{2}$ isomerization reactions important in the low-temperature chemistry (coll flame chemistry) that controls autoignition under conditions found in HCCI engines. Alongside this, MB can provide a detailed reaction mechanism of manageable size and therefore reduces computational running time without compromising accuracy level.

The authors recognize that the selection of esters MB and MF may be arguable, since the methyl oleate and methyl palmitate esters can also be considered as possible surrogates of bio-diesel fuel. Detailed investigation and validation of these esters and their reaction mechanisms are under way and will be presented in some future work, since it is beyond the scope of the current work. The properties of the investigated fuels are presented in Table 1.

The single-zone combustion model with convective heat transfer loss and detailed chemical kinetics is employed to simulate the HCCI engine environment. The effects of different engine parameters such as equivalence ratio and engine speed on ignition time are investigated. Obtained results are shown and analysed in this paper. The use of internal exhaust gas recirculation (IEGR) by trapping exhaust gases inside the cylinder is simulated as a potential strategy of controlling the ignition timing and the results obtained are also discussed.

\section{Computational Model}

The HCCI engine cylinder environment is simulated using the Aurora application from the Chemkin III modelling package [13]. The package considers the combustion chamber as a single-zone, homogeneous reactor with a variable volume. The volume is varied with time according to the slider-crank relationship. The present model assumes uniform mixture 


\begin{tabular}{|c|c|c|c|c|}
\hline & n-heptane & $\begin{array}{l}\text { Dimethyl ether } \\
\text { (DME) }\end{array}$ & $\begin{array}{l}\text { Methyl butanoate } \\
\text { (MB) }\end{array}$ & $\begin{array}{l}\text { Methyl formate } \\
\text { (MF) }\end{array}$ \\
\hline Formula & $n \cdot \mathrm{C}_{7} \mathrm{H}_{16}$ & $\mathrm{C}_{2} \mathrm{H}_{6} \mathrm{O}$ & $\mathrm{C}_{5} \mathrm{H}_{10} \mathrm{O}_{2}$ & $\mathrm{C}_{2} \mathrm{H}_{4} \mathrm{O}_{2}$ \\
\hline Molecular weight $(\mathrm{kg} / \mathrm{kmol})$ & 100 & 46 & 102 & \\
\hline Density (mol/l) & 2.3 & 5.3 & 2.94 & 5.82 \\
\hline Heat of vaporization $(\mathrm{kJ} / \mathrm{mol})$ & 36 & 20 & 33.7 & 28.6 \\
\hline Specific heat $_{\text {liq }}(\mathrm{J} / \mathrm{mol} \mathrm{K})$ & 225 & 299 & 200 & 121 \\
\hline Lower heating value (MJ/kg) & 44.9 & 28.8 & $\sim 40$ & $\sim 38$ \\
\hline Cetane number & $\sim 56$ & $60-70$ & - & - \\
\hline
\end{tabular}

Table 1 The properties of investigated fuels.

composition and thermodynamic properties treating heat loss as a distributed heat transfer proportional to the temperature difference between the average gas temperature and the time-averaged wall temperature.

The IEGR is assumed to be the internal one, with exhaust gases trapped in the cylinder and fully mixed with the fresh, unreacted air/fuel mixture. This IEGR is assumed to consist mainly of water vapour, carbon dioxide, molecular nitrogen and oxygen from previous engine cycles. The newly formed mixture (air/fuel/IEGR) is assumed to be homogeneous with uniform composition and thermodynamic properties.

The fraction of IEGR is calculated with respect to the total charge mixture mass in the cylinder (fresh air/fuel charge and trapped exhaust gases). The mixed temperature of the exhaust gases and fresh air/fuel charge is estimated assuming mixing of the ideal gases and by the published procedure [14].

The equivalence ratio $(\phi)$ is defined as that of the incoming charge in the cylinder (fresh unreacted air/fuel charge). The in-cylinder equivalance ratio $\left(\phi_{\text {in-cyl }}\right)$, which is leaner due to the residual oxygen, is calculated by the published procedure [2]. The results obtained are presented in Table 2.

Each simulation starts at the beginning of the compression stroke (inlet valve closure, or IVC) and finishes at the end of the expansion stroke, with a time step of $1^{\circ}$ crank angle (CA). The cylinder wall, piston and head are all assumed to be at the uniform temperature of $500 \mathrm{~K}$.

\begin{tabular}{|lll|}
\hline IEGR (\% mass) & $\phi$ & $\phi_{\text {in-cyl }}$ \\
\hline 0 & 0.5 & 0.5 \\
10 & 0.5 & 0.47 \\
20 & 0.5 & 0.44 \\
30 & 0.5 & 0.41 \\
40 & 0.5 & 0.37 \\
50 & 0.5 & 0.33 \\
60 & 0.5 & 0.28 \\
70 & 0.5 & 0.23 \\
\hline
\end{tabular}

Table 2 The in-cylinder equivalence fuel-air ratio as a function of IEGR.
The chemical kinetic mechanisms employed for $n$-heptane and DME are those developed by Lawrence Livermore National Laboratory $[15,16]$, while the kinetics mechanism for MB and MF are those developed by Lawrence Livermore National Laboratory and Fisher et al. [12].

The mechanism for $n$-heptane consists of 565 species and 2540 reactions, and for DME of 78 species and 336 reactions. The mechanism for MB consists of 264 species and 1219 reactions and for MF of 193 species and 925 reactions. All these mechanisms have been validated through extensive comparisons with experimental data obtained from the measurement conducted in flow reactors, shock tubes and rapid compression machines [12, 15-18].

\section{Engine Description}

The engine is assumed to have a bore of $80.5 \mathrm{~mm}$ and a stroke $88.2 \mathrm{~mm}$. The connecting rod length is $132 \mathrm{~mm}$, with a displacement of $450 \mathrm{~cm}^{3}$. The engine is assumed to have a fully variable valve train (FVVT) system, instead of conventional camshafts, which allows trapping of large amounts of exhaust gases (up to 80 per cent) and quick changes in the trapped percentage in comparison to the engine with a camshaft [3]. This arrangement allows a nearadiabatic exhaust gas recirculation (EGR) process, which means that the mixture temperature rises with the percentage of EGR. The engine is assumed to be unthrottled at all operational points with a volumetric efficiency of 100 per cent. The simulation requires no information on which type of valve system is used. However, an HCCI engine equipped with the FVVT system allows near-adiabatic exhaust gas recirculation and unthrottled operations that are important for the assumptions made in the used computational model.

\section{Validation of the Model}

The results obtained by using the computational model are validated against the experimental results. 
The experiment was performed on the single-cylinder, four-stroke engine equipped with the AVT-Lotus research active valve train system [the FVVT system is also called the active valve train (AVT) system] and fuelled with $n$-heptane. The experiment, engine and AVT have been discussed in detail in references [19] and [20]. Test conditions are summarized in Table 3.

The engine operational parameters and conditions used in the simulation were the same as those used in the experiment. The heat release rate is calculated from the pressure values at each time step using the KINALC post-processor code [21].

In Fig. 1, the comparison between the calculated and measured cylinder pressure and heat release rate curves is shown. It can be seen that the general shape of the calculated cylinder pressure curve corresponds rather well with the experimental one. The peak cylinder pressure is overpredicted due to the deficiency of the single-zone assumption to model the temperature gradient within the mixture.

The overall trend of the heat release curve is matched, but the calculated values are overpredicted and the duration is underpredicted. This is due to the assumption (of a single-zone model) that the whole mixture inside the cylinder will burn almost simultaneously and completely. In reality a boundary layer that contains significant mass will exist and will be at a lower temperature than the bulk gas near TDC. Consequently, the boundary layer will always

$\begin{array}{ll}\text { Bore } & 80.5 \mathrm{~mm} \\ \text { Stroke } & 88.2 \mathrm{~mm} \\ \text { Swept volume } & 450 \mathrm{~cm}^{3} \\ \text { Number of valves per cylinder } & 4 \\ \text { Valves control } & \text { Electrohydraulic Lotus AVT system } \\ \text { Indicated mean effective pressure (i.m.e.p.) } & 3 \mathrm{bar} \\ \varepsilon & 10.5 \\ \text { Speed } & 2000 \mathrm{r} / \mathrm{min} \\ \text { Inlet pressure } & \text { Naturally aspirated } \\ \text { IEGR } & 55 \% \text { (by mass) } \\ \text { Fuel } & n \text {-heptane } \\ \text { Equivalence air-fuel ratio } & \text { Stoichiometric } \\ \text { Inlet temperature } & 25^{\circ} \mathrm{C} \\ \text { Water/oil temperature } & 92^{\circ} \mathrm{C} \\ \end{array}$

Table 3 Specification of the research single-cylinder engine and test conditions.

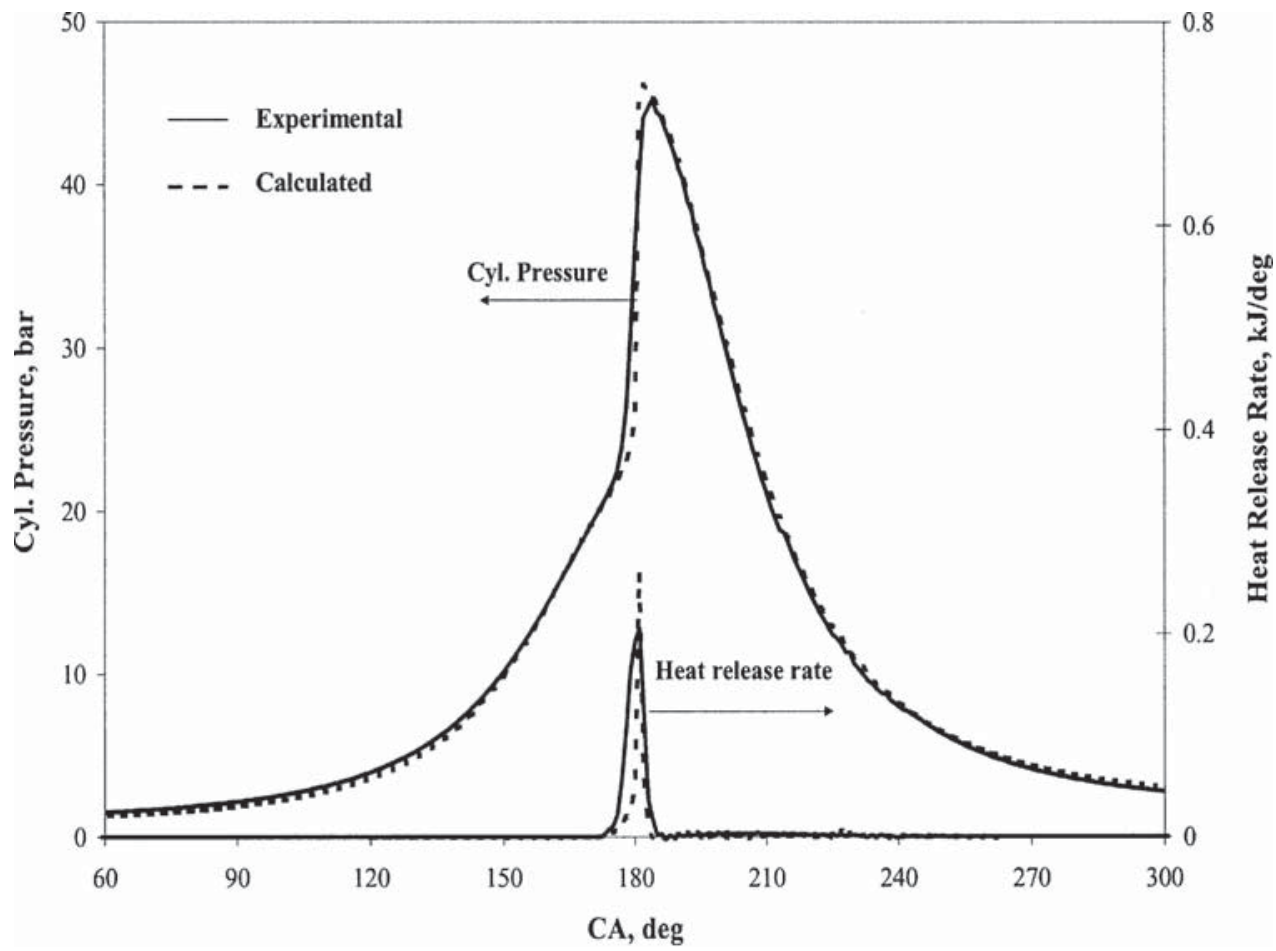

Fig. 1 Comparison of calculated and experimental cylinder pressure and heat release rate curves for n-heptane fuel. 
burn last and extend the heat release rate compared to this simulation. In addition, some fuel will be captured in crevices and piston rings and will not be burned, thus reducing the total heat release.

The authors recognize that model assumptions are an oversimplification of the actual condition within the engine cylinder which leads to overestimation of the peak cylinder pressure and rate of pressure rise, an underestimation of burn duration and an inability to accurately predict $\mathrm{HC}$ and $\mathrm{CO}$ emissions. On the other hand, prediction of the start of ignition is shown to be accurate. This notion has also been confirmed in references [22] and [23].

\section{Results and Discussion}

In practical transport applications, an HCCI engine will be the same as SI and CI engines in that there will be frequent changes between operation in idle, acceleration, de-acceleration and steady cruise modes. These changes in operational mode are accomplished by changes in engine power output (load) and speed. In that way it is expected that the HCCI engine has to be able to work over a wide range of loads and speeds.

In order to make it possible for an HCCI engine to work with a wide range of loads and speeds and to achieve a high efficiency, the autoignition timing and heat release rate have to be properly phased (controlled). For optimal engine efficiency, the ignition should occur near TDC compression, $180^{\circ} \mathrm{CA}$. If the ignition is too advanced it will increase compression effort, reduce volumetric efficiency and thus reduce net thermal efficiency. On the other hand, very late ignition will cause a lower combustion temperature, higher emissions of unburned HC and reduce combustion efficiency. The ignition timing is readily seen to produce a sharp rise in the cylinder pressure or temperature. In this study the baseline engine parameters are those summarized in Table 4.
In Fig. 2 the calculated cylinder pressure curves are presented as a function of crank angle degree. Due to the different structure of the analysed fuels and in order to obtain ignition near TDC, the inlet mixture temperature was adjusted for each fuel separately. It can be seen that DME needs the lowest inlet temperature $(298 \mathrm{~K})$ while MF needs the highest (465 K). The inlet temperature for $n$-heptane is $320 \mathrm{~K}$ and is close to that of DME but much lower than the value for MB (435 K).

Different ignition behaviours and therefore different ignition temperatures are a consequence of the different structures, compositions and molecular sizes of examined fuels. These differences have the important consequence of controlling HCCI combustion over a wide operational range.

It can be seen from Fig. 2 that $n$-heptane and DME exhibit dual-stage ignition, with a cool flame (CF or low-temperature ignition) and main ignition (MI or high-temperature ignition). On the other hand, MB and MF undergo single-stage ignition only.

$n$-Heptane is a long straight-chain paraffin with many weakly bounded $\mathrm{H}$ atoms with high isomerization rates which leads to rapid ignition. The $\mathrm{CF}$ ignition is mainly due to the presence of $\mathrm{C}_{7} \mathrm{H}_{15}$ radicals, which ultimately leads to a relatively high rate of chain branching from ketohydroperoxide decomposition [18, 24]. It can be seen (refer to Fig. 2) that between the CF and the MI there exists an 'induction period' which corresponds to the intermediate temperature zone (900-1100 K). The induction period is associated with competition between the fast chain branching reactions and relatively slower chain propagation reactions. In this period, chain propagation reactions dominate, causing the slowdown of $n$-heptane reactivity and therefore only gradual accumulation of the radical pools and gradual temperature rises occur.

When the temperature has reached a value of around $1100 \mathrm{~K}$, the high-temperature chain branching reactions start to dominate again and the main ignition

$\begin{array}{ll} & \\ \text { Bore } & 80.5 \mathrm{~mm} \\ \text { Stroke } & 88.2 \mathrm{~mm} \\ \text { Swept volume } & 450 \mathrm{~cm}^{3} \\ \varepsilon & 14 \\ \text { Speed } & 2000 \mathrm{r} / \mathrm{min} \\ \text { Equivalence fuel-air ratio } & \phi=0.5 \\ \text { Intake temperature } & \text { Varied } \\ \text { Inlet pressure } & \text { Naturally aspirated } \\ \text { Cylinder wall temperature } & 500 \mathrm{~K} \\ \text { Fuel } & n \text {-Heptane, dimethyl ether (DME), methyl butanoate (MB) and methyl formate (MF) } \\ \end{array}$

Table 4 Baseline engine operational parameters. 


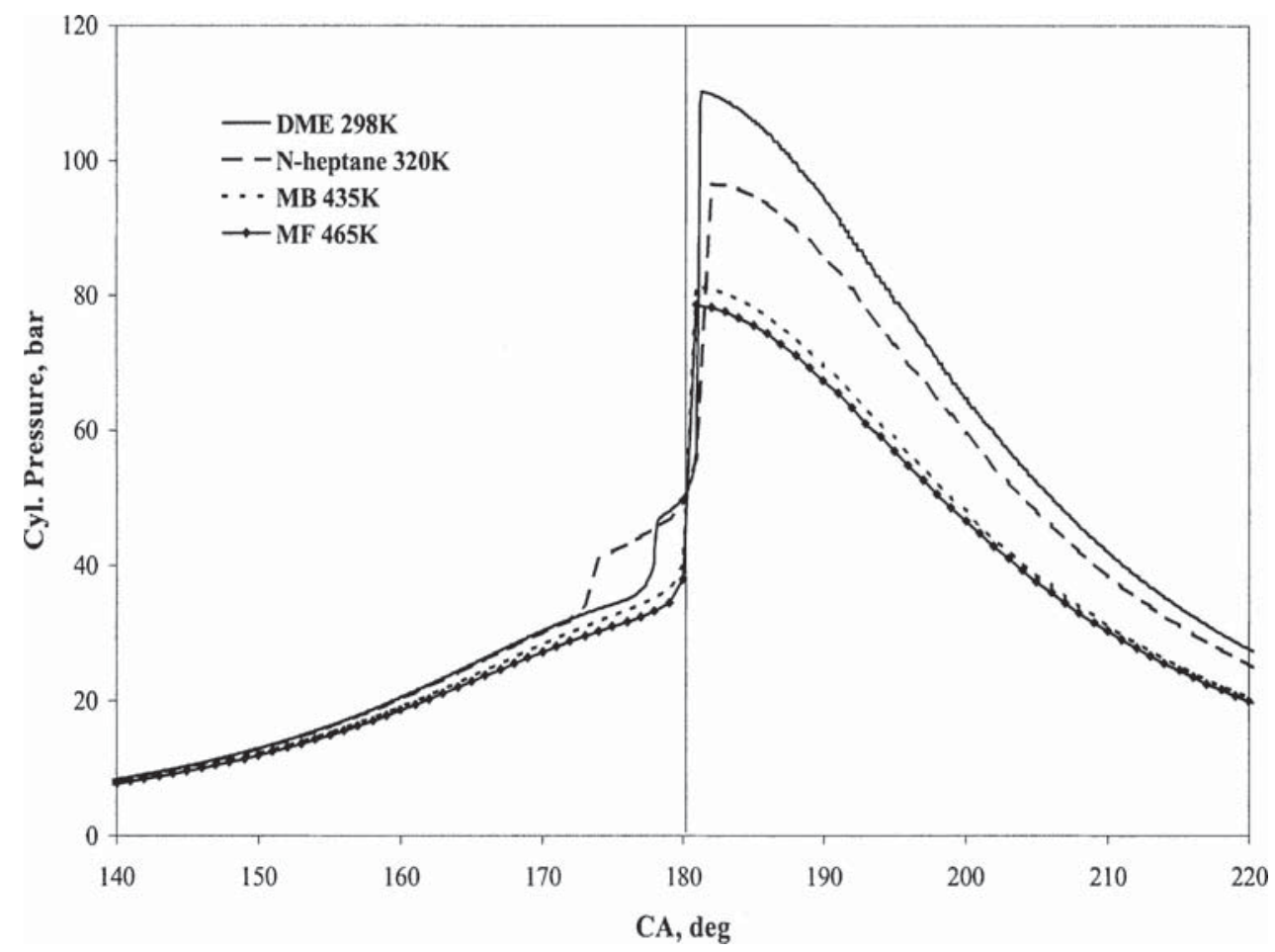

Fig. 2 Cylinder pressure as a function of crank angle for n-heptane DME, MB and MF fuels.

occurs. The main high-temperature chain branching reaction, which dominates the further ignition process, is the reaction

$$
\mathrm{H}+\mathrm{O}_{2}=\mathrm{O}+\mathrm{OH}
$$

which is essentially independent of the type of fuel $[25,26]$.

DME is the simplest ether (and oxygenated fuel), which instead of $\mathrm{C}^{-} \mathrm{C}$ bonds, has the $\mathrm{C}^{-} \mathrm{O}^{-} \mathrm{C}$ bond. Non-existence of the $\mathrm{C}-\mathrm{C}$ bonds makes DME more favourable for the ignition in comparison to $n$-heptane, and therefore a lower initial temperature is needed. It can be noted that the induction period for $n$-heptane is considerably longer than that for DME (refer to Fig. 2). This is a consequence of the peroxy chemistry which plays the dominant role in DME ignition, maintaining the radical branching reactions (in the induction period) and thus keeping the reactivity of the fuel unchanged [27].

$\mathrm{MB}$ and MF show single-stage ignition only, due to the presence of the methyl and olefinic methyl ester groups. These radical groups have much lower reactivity in comparison to $\mathrm{C}_{7} \mathrm{H}_{15}$ radicals in $n$-heptane and peroxy radicals in DME, and therefore the cool flame chemistry in MB and MF fuel is considerably inhibited. In conjunction with this, methyl and methyl ester radicals slow down the overall rate of ignition, since they lead to chain termination reactions [27].
Therefore, to ignite MB and MF considerably higher temperatures are necessary than those for $n$-heptane and DME.

These differences in ignition mechanisms will have a significant influence on the ignition timing during various operational conditions (various fuelling rates and engine speeds).

\section{Effect of the Equivalence Ratio}

Load variation in an HCCI engine is studied by varying the equivalence fuel-air ratio $(\phi)$. In the Chemkin code there is no direct possibility of simulating variations in engine load. Because changes in the power output of an HCCI engine are closely connected with changes in the fuelling rate (charge composition), the effect of the equivalence ratio can be used to simulate changes in the charge composition. Changing the load of an $\mathrm{HCCI}$ engine requires a change in the fuelling rate and thus in the charge composition. Figure 3 shows the influence of different $\phi$ values on the ignition timing of $n$-heptane, DME, MB and MF. Inlet temperatures and other engine parameters remain unchanged from the baseline values stated in section 5 .

It can be noted that $\phi$ has rather different effects on the ignition timing of analysed fuels that depend on fuel autoignition behaviour. For fuels with two-stage 


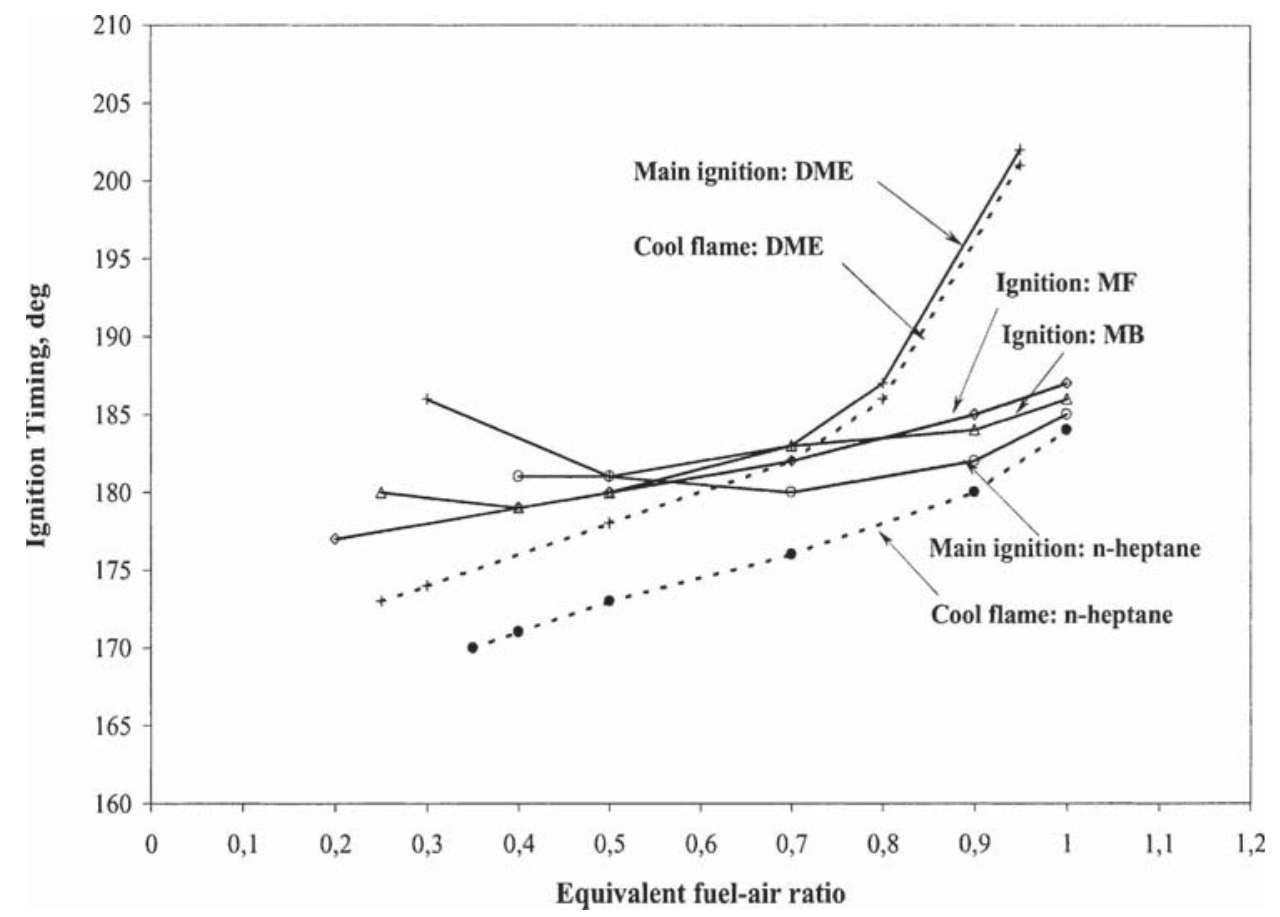

Fig. 3 Effect of the equivalence fuel-air ratio on ignition timing for n-heptane, DME, MB and MF fuels. Symbol $(\bigcirc)$ represents n-heptane main ignition, (-) n-heptane cool flame ignition, (+ and solid line) DME main ignition, (+ and dashed line) $D M E$ cool flame ignition, $(\triangle) M B$ and $(\diamond) M F$. The solid line corresponds to the main ignition while the dashed line corresponds to the cool flame ignition.

ignition, such as $n$-heptane and DME, changing $\phi$ has an impact on the onset of cool flame and main ignition, magnitude of the initial pressure increase and duration of the induction time. On the other hand, for fuels with single-stage ignition, such as $\mathrm{MB}$ and $\mathrm{MF}$, only the onset of the main ignition is affected by $\phi$.

In order to represent variations in all phases of the two-stage ignition process with changes in $\phi$, the cylinder pressure histories as a function of crank angle degree for different values of $\phi$ are shown for $n$-heptane fuel in Fig. 4a and for DME fuel in Fig. $4 \mathrm{~b}$. As $\phi$ increases, the ratio of specific heats $(\gamma)$ for the mixture decreases, reducing the amount of compression heat of the mixture. Therefore, a nearstoichiometric mixture has to be compressed further than a lean mixture in order to attain a temperature sufficient to initiate CF ignition. Increases in $\phi$ from 0.3 to 1.0 for $n$-heptane results in a delay in the $\mathrm{CF}$ timing of approximately $12^{\circ} \mathrm{CA}$, while for DME increasing $\phi$ from 0.25 to 0.95 delays CF ignition for approximately $27^{\circ} \mathrm{CA}$, as can be noted in Figs $4 \mathrm{a}$ and $\mathrm{b}$ respectively. It is obvious that the $\mathrm{CF}$ ignition timing of DME is affected more with a change in the equivalence ratio. This is due to the nature of the lowtemperature chain branching processes, responsible for the CF ignition in DME and $n$-heptane. The peroxy radical chemistry controls the low-temperature chain branching process in DME, while the $\mathrm{C}_{7} \mathrm{H}_{15}$ radical chemistry controls it in $n$-heptane. The production of peroxy radicals is more sensitive to the changes in temperature and fuel concentration than the production of $\mathrm{C}_{7} \mathrm{H}_{15}$ radicals. Therefore, a reduced temperature rise and increased fuel concentrations will have a more pronounced influence on $\mathrm{CF}$ ignition in DME.

The magnitude of the $\mathrm{CF}$ ignition temperature rise depends on $\phi$. Excess air acts as a diluent which absorbs heat and reduces the temperature rise from $\mathrm{CF}$ reactions as the mixture becomes leaner ( $\phi$ decreases). Therefore, in order to reach the temperature of the MI stage $(1100 \mathrm{~K})$, more heating is required during the induction period for leaner mixtures. During this period, heat is slowly generated by the chemical reactions and the temperature is further raised by compression (prior to TDC). The net result is an increase in the induction period as the mixture becomes leaner.

Therefore, it can be said that the overall ignition timing of $n$-heptane and DME is affected by $\phi$, through two competing effects:

(a) the strength of the CF ignition reactions-heat released by low temperature oxidation-and

(b) the amount of compression heating due to the changes in the mixture specific heat $(\gamma)$-heat released by piston compression work. 

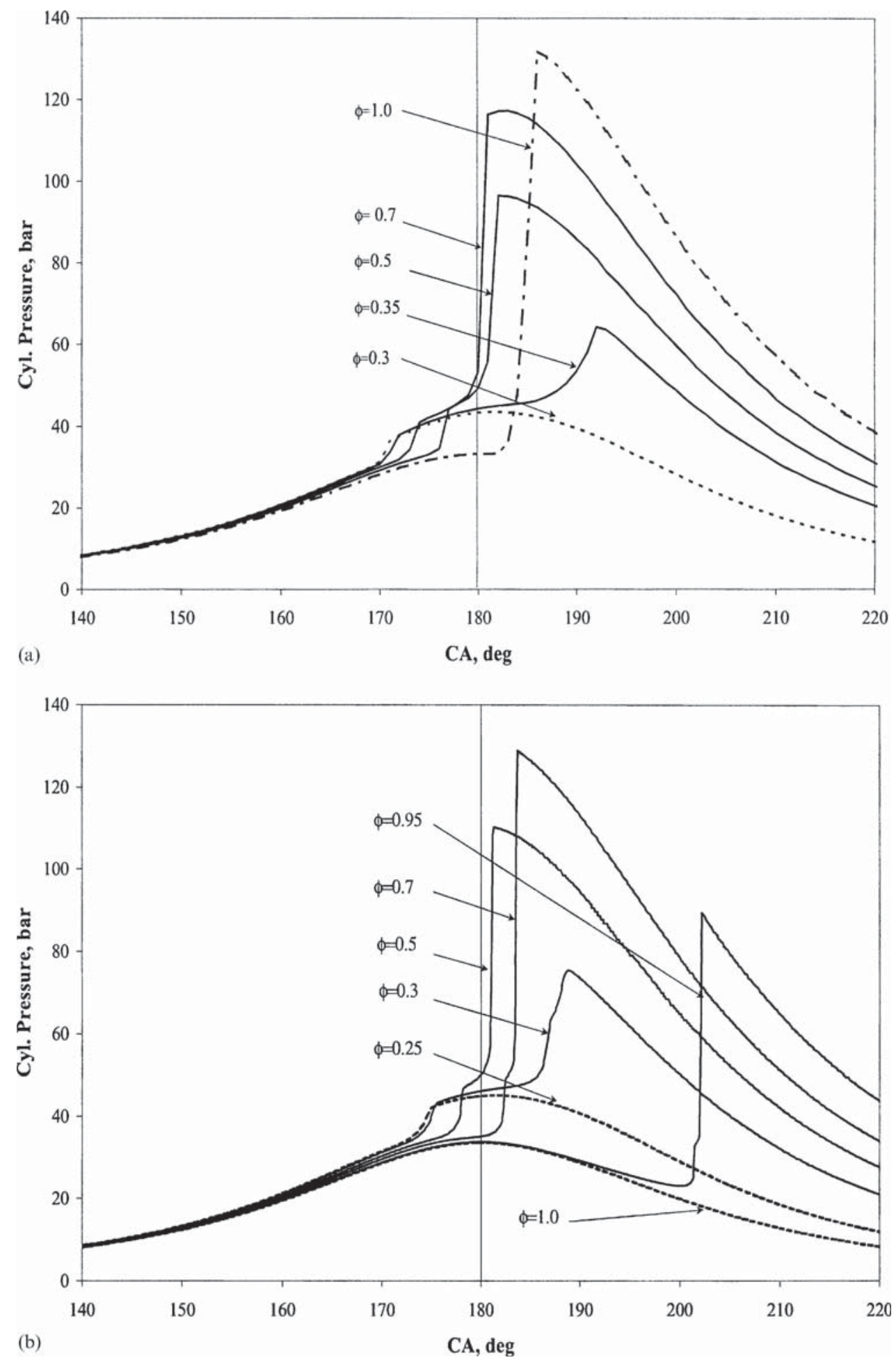

Fig. 4 Cylinder pressure as a function of crank angle and $\phi$ for (a) n-heptane and (b) DME fuels.

As shown in Fig. 4, the earliest CF ignition occurs for $\phi$ of 0.3 for $n$-heptane and 0.25 for DME, but the associated temperature rise is not sufficient to lead to MI. When $\phi$ is increased to 0.35 for $n$-heptane and to 0.3 for DME, MI occurs, although after TDC. As $\phi$ continues to increase, CF ignition occurs later, but the induction period becomes shorter. The result of this is that MI occurs at the earliest time for $\phi$, which is equal to 0.7 for $n$-heptane. However, MI becomes retarded again at higher equivalence ratios. The onset of main ignition for DME fuel exhibits similar behaviour to that for $n$-heptane fuel. At first it advances as $\phi$ increases, but later, for higher $\phi$, it retards again. Additionally, it must be noted that DME neither exhibits CF ignition nor MI for $\phi$ equal to 1 (stoichiometric mixture). This is a highly likely 
consequence of a low inlet temperature (i.e. below the value necessary to initiate a CF ignition event). The temperature required to initiate the CF ignition increases with an increase in the fuel amount in the charge, and therefore fuel-rich mixtures will need a higher initial temperature than fuel lean mixtures. For investigated conditions, the initial temperature (298 K) was not sufficient enough to initiate CF ignition and thus there was no heat release from low-temperature reactions; hence the ignition could not proceed further into the intermediate and main ignition stages. The results obtained are in agreement with the test results presented in reference [28]. It can be noted that the applicable range for $n$-heptane is extended towards higher $\phi$ values than DME, while DME exhibited a lower flammability limit than $n$-heptane.

In the case of $\mathrm{MB}$ and $\mathrm{MF}$, fuels with single-stage ignition behaviour, the ignition timing is also affected by $\phi$, as can be seen in Fig. 3. Due to the fact that their ignition is characterized by a single-stage process, ignition timing is mainly affected by changes in heat capacity and proportional changes in compression temperature. Therefore, the ignition time becomes delayed as $\phi$ increases.

For $\mathrm{MB}$, increases in $\phi$ from 0.2 to 0.5 has virtually no effect on the ignition timing (refer to Fig. 5a). When a higher equivalence ratio is employed $(>0.5)$, the ignition becomes delayed. Therefore, for MB fuel increasing in $\phi$ from 0.2 to 1 results in an ignition delay of approximately $7^{\circ} \mathrm{CA}$. The ignition timing for MF fuel is slightly more affected with the changes in equivalence ratio in comparison to $\mathrm{MB}$ fuel, resulting in delays of $10^{\circ} \mathrm{CA}$ over the range of $\phi$ from 0.15 to 1 , as can be seen in Fig. $5 b$.

It can be seen from Fig. 3 that MB and MF fuels have lower flammability limits in comparison to $n$-heptane and DME fuel, since they can sustain complete combustion for $\phi$ lower than 0.3. Alongside this, the changes in ignition timing for $\mathrm{MB}$ and $\mathrm{MF}$ fuels over the applicable $\phi$ range are much lower (7 and $10^{\circ} \mathrm{CA}$ respectively) than those for $n$-heptane and DME fuels. Moreover, MB and MF can ignite even for lower equivalence ratios up to $\phi=0.05$ (not shown), but this leads to incomplete or partial combustion.

The commercial HCCI engine would need to operate over a range of equivalence ratios from 0.1 or less (idle) to about 1 . The competing factors presented in the two-stage ignition processes of $n$-heptane and DME indicate that controlling the ignition timing with changes in $\phi$ will be more difficult in these fuels than in the MB and MF fuels. Also, a significant increase in the cylinder temperature would be required to maintain combustion at low loads $(\phi<0.3)$ for the n-heptane and DME fuels.

\section{Effect of Engine Speed}

In operation an HCCI engine will face frequent de-acceleration and acceleration and hence a change in speed. Changing the engine speed changes the amount of time for the autoignition chemistry to occur relative to the piston motion. The chemical reaction rates are sufficiently slow (relative to the engine speed) to cause all analysed fuels ignition timings to be delayed with the increase in engine speed. The ignition is retarded with respect to crank angle degree. The autoignition chemistry has a fixed timescale independent of engine speed, but the piston motion becomes faster with an increase in engine speed, which in turn reduces the engine cycle duration and therefore a time base for the autoignition chemistry.

Inlet temperatures and other engine parameters remain unchanged from the baseline values stated in section 5. Figure 6 shows the influence of engine speed on ignition timings for $n$-heptane and DME, while Fig. 7 shows the influence for MB and MF. It can be seen that engine speed has a rather different effect on ignition for fuels with a two-stage ignition behaviour than on fuels with single-stage ignition behaviour.

For $n$-heptane and DME, as the engine speed increases CF ignition occurs at later crank angles (refer to Fig. 6). The induction time is also longer as speed increases, and thus MI timing is further retarded. If ignition occurs before TDC, the charge temperature rise from compression compensates for this effect by reducing the induction period. However, for ignition after TDC, the induction period increases since expansion slows down the temperature rise. For the conditions at this simulation, the difference in ignition timing for engine speed ranging from 1000 to $3000 \mathrm{r} / \mathrm{min}$ is $21^{\circ} \mathrm{CA}$ for $n$-heptane and $13^{\circ} \mathrm{CA}$ for DME.

The dependence of ignition on engine speed for $\mathrm{MB}$ and MF fuels is presented in Fig. 7. The trend is similar to that for $n$-heptane and DME, but with less variation in ignition timing. The reason for this is the nature of the chemistry that leads to single-stage ignition of these fuels. This chemistry proceeds faster once the temperature reaches the value of hightemperature chain branching reactions. Then the main high-temperature chain branching reaction, reaction 1 (which is essentially independent of the types of fuel), 

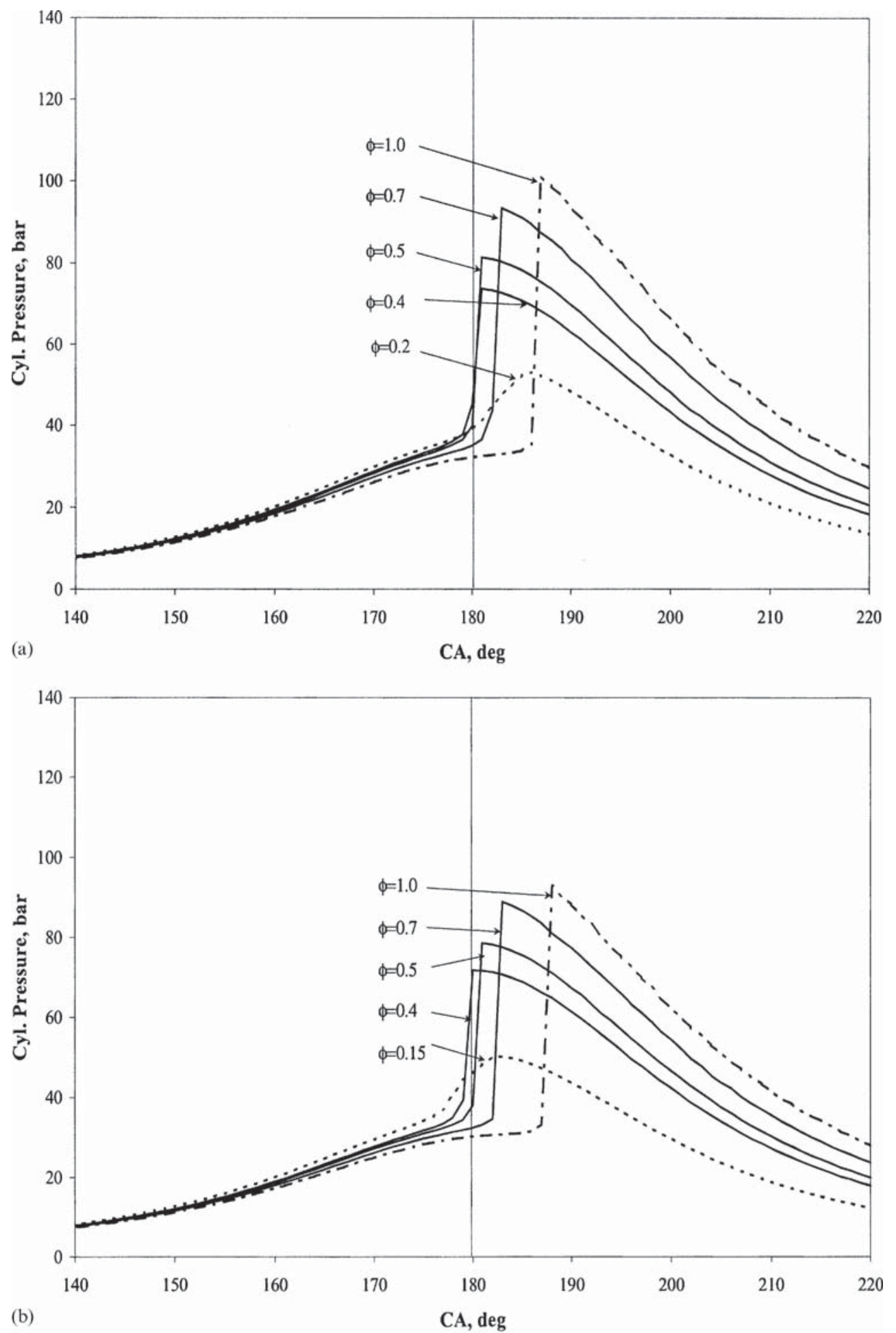

Fig. 5 Cylinder pressure as a function of crank angle and $\phi$ for (a) MB and (b) MF fuels.

takes over control of the further ignition process. Therefore, the ignition in MB and MF fuels is not affected by changes in the CF stage. As a result, the differences in ignition timings for $\mathrm{MB}$ and $\mathrm{MF}$ fuels over the examined range of engine speeds (1000-3000 r/min) are 14 and $16^{\circ}$ CA respectively, which are less than that for $n$-heptane fuel.

It is worth noting that DME fuel exhibits the lowest variation of ignition timings with respect to changes in engine speed due to its fast peroxy chemistry, as discussed in section 6, followed by MB and MF fuels. The authors would like to emphasize that the investigation of the engine speed effect on ignition timing over the examined range (1000-3000 r/min) was performed with an assumption of a cylinder wall temperature of $500 \mathrm{~K}$. Since the heat transfer to the wall will increase with an increase in engine speed there would be some increase in the wall 

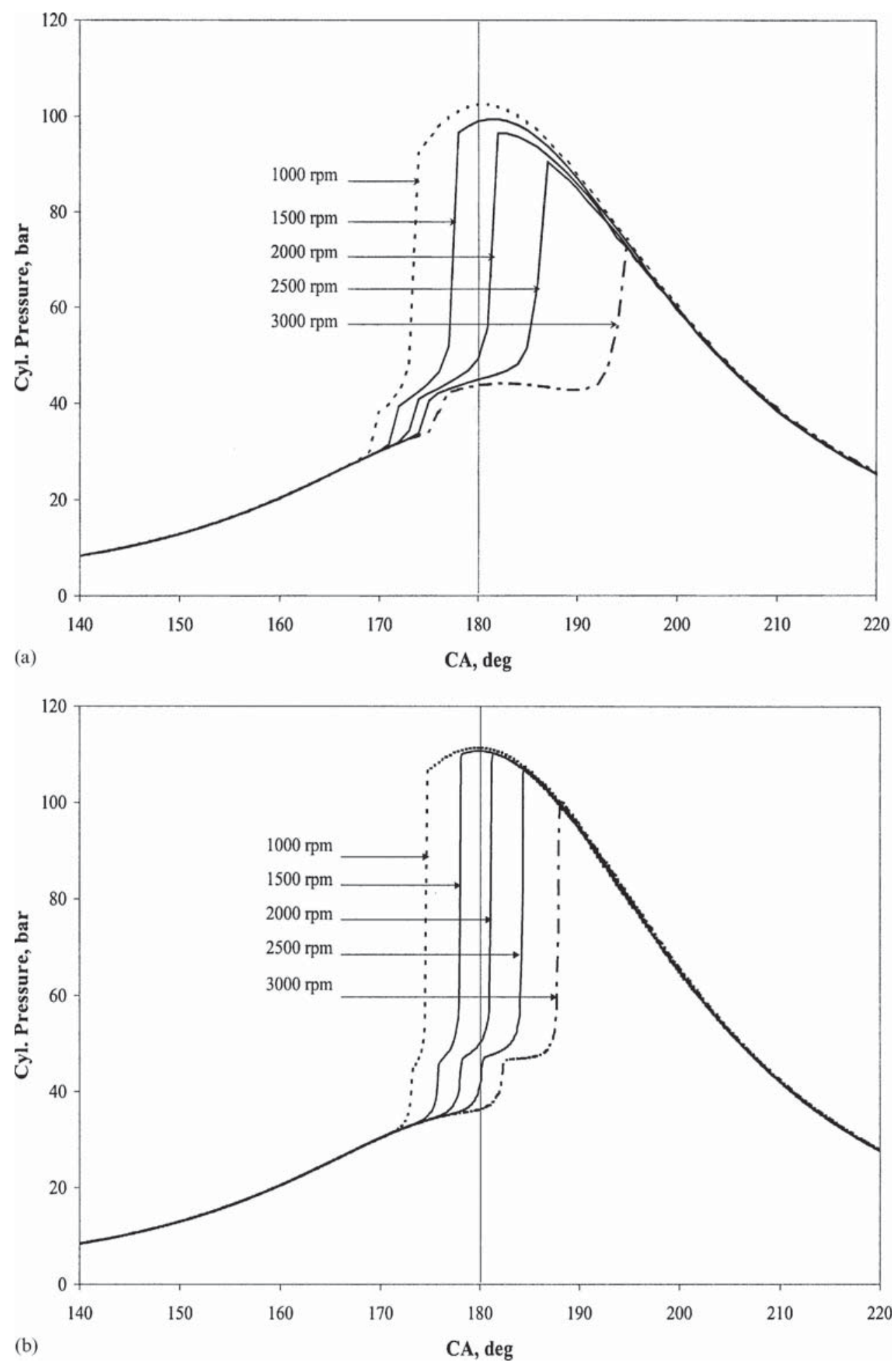

Fig. 6 Cylinder pressure as a function of crank angle and engine speed for (a) n-heptane and (b) DME fuels.

temperature. This may affect the autoignition process (i.e. the ignition may occur at earlier crank angle). However, previous investigations have demonstrated that HCCI combustion is too fast for heat transfer to play an important role in the prediction ignition timing $[29,30]$ and that errors obtained from the use of inaccurate heat transfer correlations are within the range of $0.1-1$ per cent.
Although fuels with a single-stage ignition process have less variation in ignition timing with engine speed than $n$-heptane, some adjustment is required for each of the fuels to maintain the optimum ignition timing. This could be accomplished by adjusting the operational parameters such as intake temperature and pressure or compression ratio. In the practical case, intake temperature could be controlled by EGR. 


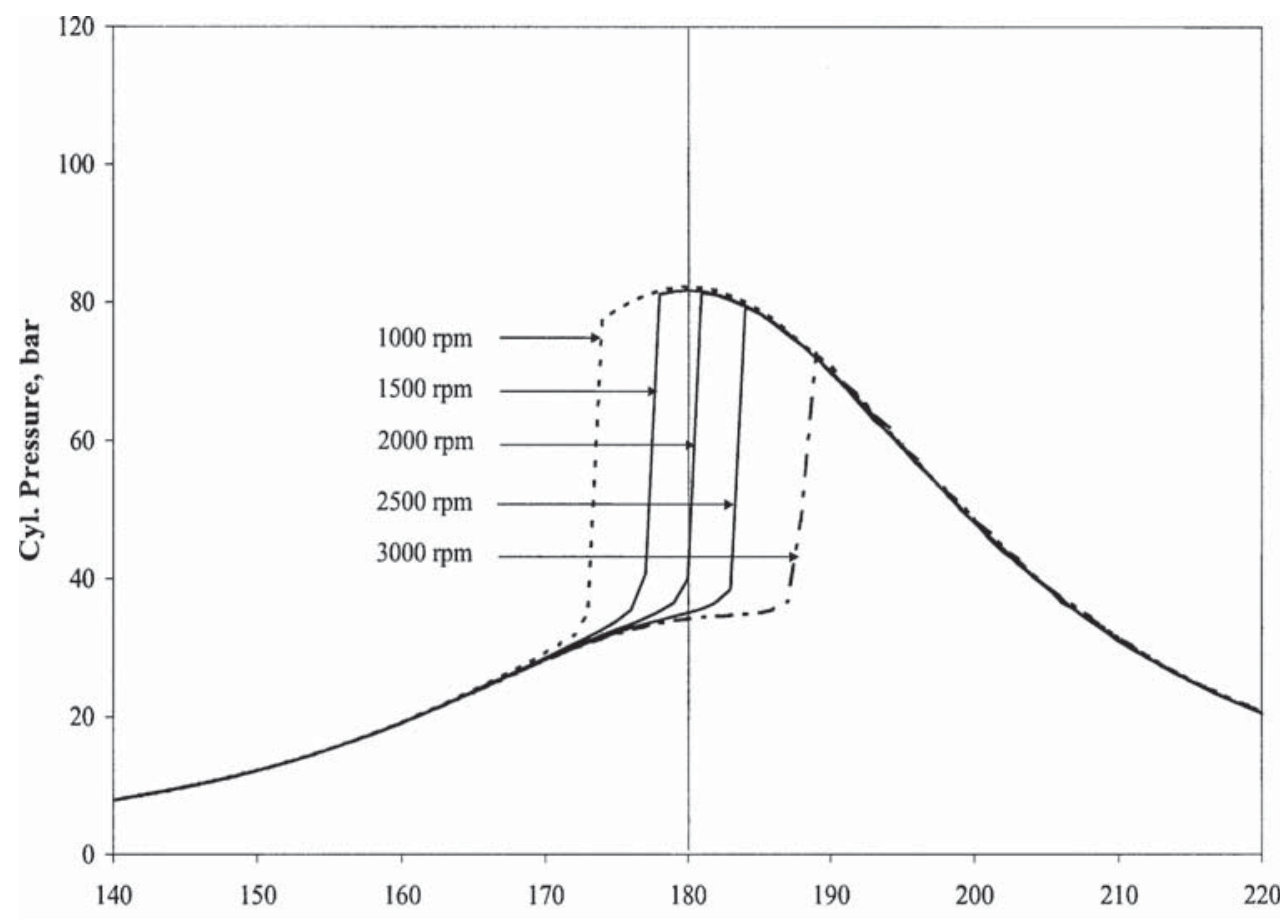

(a)

CA, deg

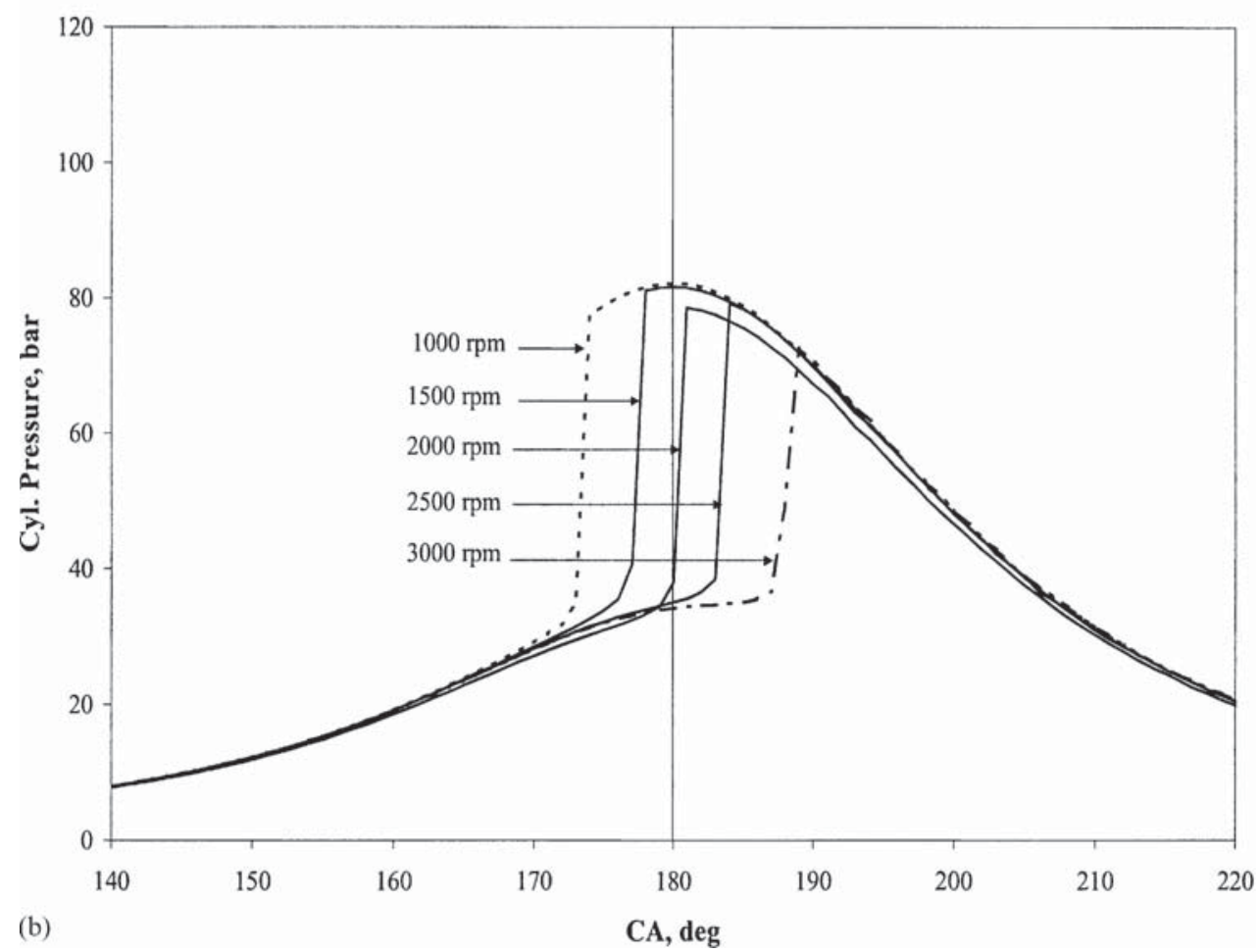

Fig. 7 Cylinder pressure as a function of crank angle and engine speed for (a) MB and (b) MF fuels.

\section{Controlling Ignition Timing in the $\mathrm{HCCl}$ Engine by Using Internal Gas Recirculation}

Exhaust gas recirculation (EGR), obtained by trapping the hot exhaust gases in the cylinder (internal EGR, or IEGR) or recycling them into the intake manifold (external EGR, or EEGR), appear to have the potential to control HCCI combustion in a certain operation range. IEGR obtained by the fully variable valve train (FVVT) system gives much better results in controlling the HCCI combustion process than using EEGR [2, 3, 5].

When using the IEGR technique, a fresh airfuel charge is mixed with hot trapped exhaust gases, increasing the temperature and changing the composition of the newly formed charge mixture (air/fuel/IEGR) and thus influencing the ignition 
timing and further combustion process. In order to initiate autoignition and maintain HCCI combustion a certain amount of IEGR has to be captured. This amount depends on engine operating conditions (engine load and speed) and fuel used.

In Fig. 8, the cylinder pressure histories obtained for various quantities of IEGR for an engine fuelled with $n$-heptane and DME are presented, while Fig. 9 shows those for engines fuelled with MB and MF. The engine parameters are those summarized in Table 5 .
It can be seen that with trapping a higher IEGR percentage, the CF and MI timings for $n$-heptane and DME fuels are advanced (refer to Fig. 8). The CF timing is more affected than the MI timing as a result of the elevated charge temperatures earlier in the cycle. The MI timing, as discussed in section 6, depends on two competing factors, namely the amount of compression heating and the strength of the low-temperature reactions.

As MB and MF have a lower reactivity, relatively high intake temperatures are needed to initiate the
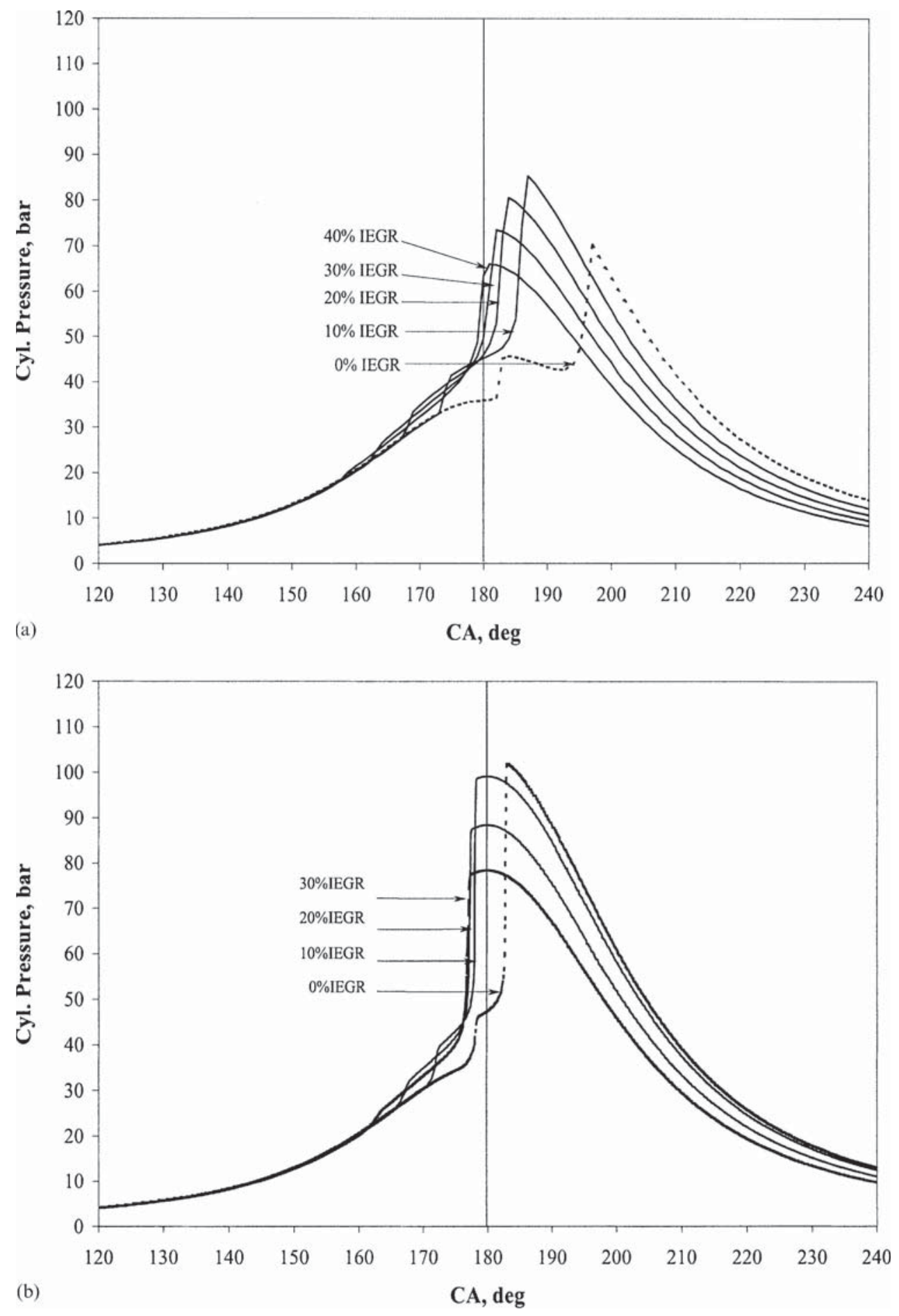

Fig. 8 Cylinder pressure as a function of different IEGR quantities for (a) n-heptane and (b) DME fuels. 

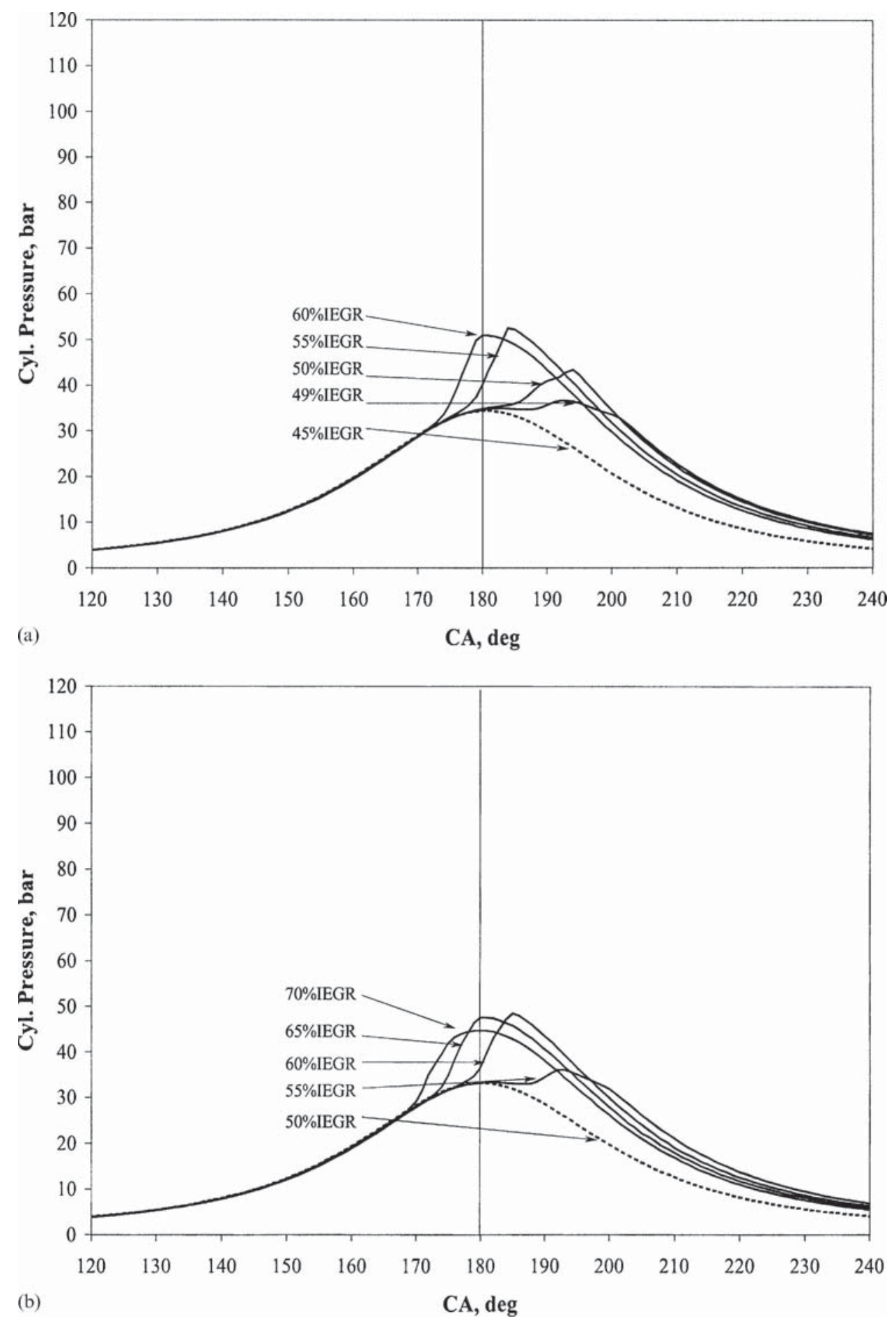

Fig. 9 Cylinder pressure as a function of different IEGR quantities for (a) MB and (b) MF fuels.

ignition process in these fuels. Therefore, a high amount of IEGR has to be employed, 49 per cent for MB and 55 per cent for MF (refer to Fig. 9). These IEGR quantities represent the minimum values necessary for complete combustion of $\mathrm{MB}$ and MF fuels, and thus their ignitability limits under given operational conditions. It can be seen that for all analysed fuels the peak cylinder pressure decreases with an increased IEGR level (refer to Figs 8 and 9).
It is also worthy of note that the ignition initiated with IEGR around TDC [with 20 per cent IEGR for $n$-heptane (Fig. 8) and with 55 per cent IEGR for MB and 60 per cent IEGR for MF (Fig. 9)] results in a significant reduction in peak cylinder pressure in comparison to the case without using IEGR (refer to Fig. 2). This is due to the dual effects of IEGR, thermal and chemical. It is worth noting that when a higher value of IEGR is trapped, the amount of 


\begin{tabular}{ll|} 
Bore & $80.5 \mathrm{~mm}$ \\
Stroke & $88.2 \mathrm{~mm}$ \\
Swept volume & $450 \mathrm{~cm}^{3}$ \\
$\varepsilon$ & 14 \\
Speed & Varied \\
Equivalence fuel-air ratio & Varied \\
Intake temperature & $298 \mathrm{~K}$ \\
IEGR temperature & $800 \mathrm{~K}$ \\
IEGR quantity & Varied \\
Inlet pressure & Naturally aspirated \\
Cylinder wall temperature & $500 \mathrm{~K}$ \\
Fuel & $n$-Heptane, dimethyl ether (DME), methyl butanoate (MB) and methyl formate (MF) \\
\hline
\end{tabular}

Table 5 Engine operational parameters for the analysis of IEGR effects.

fresh air/fuel charge is reduced, which results in a lower load output and also in lower generated torque. Consequently, the engine, at lower power, reduces combustion temperature, hence produces a lower temperature of exhaust gases. In the following text only a basic explanation of these effects and their influence on the ignition timing will be presented, as detailed explanations have been presented in references [31] to [34] and it is beyond the scope of the current study.

The thermal effect of IEGR consists of raising the temperature of the fresh air-fuel intake charge in the mixing process with hot exhaust gases, which thus influences the ignition timing and further combustion. A higher temperature boosts kinetic reactivity (chemical reactivity), resulting in the advance of autoignition. The higher chemical reactivity increases the heat release which in turn increases the charge energy level. The increased charge energy level helps to overcome certain activation energy levels for autoignition at an earlier stage; hence the autoignition is advanced. Therefore, the IEGR thermal effect is similar to the effect of increasing the inlet temperature (inlet pre-heating) since it improves the pre-ignition stage process by boosting kinetic reactivity. The thermal effect of IEGR can be seen as being positive for the HCCI engine since it reduces the necessity for the inlet air pre-heating and eliminates the dependence on the operating conditions.

The chemical effect of IEGR actually consists of several different effects that take place simultaneously*:

1. Heat capacity effect. IEGR increases the specific heat of the charge mixture (air/fuel/IEGR) due to the presence of exhaust gas species which have a higher heat capacity than the fresh air-fuel charge.

*This division may be arguable. Some authors $[33,34]$ claimed that there are five different effects of IEGR: thermal, heat capacity, dilution, the effect of increasing $\mathrm{H}_{2} \mathrm{O}$ and $\mathrm{CO}_{2}$ concentration and the effect of IEGR constituents on some reactions.
2. Dilution effect. The introduction of exhaust gases into the cylinder results in the dilution of the charge mixture. Dilution may be up to 80 per cent of cylinder volume. The introduction of exhaust gases into the cylinder displaces some air from the fresh air-fuel charge. Hence, the oxygen concentration in the resulting charge mixture is reduced. At the same time some fuel is displaced from the fresh air-fuel charge. In this way the charge mixture becomes diluted. The reduction in oxygen and fuel concentrations together with added exhaust gases will result in a changed fuel-air ratio in the resulting charge mixture.

3. Increasing the concentration of some exhaust gas species. IEGR raises the concentration of water vapour and carbon dioxide which tends to reduce their net production rate.

4. Influencing the radical production and destruction reactions. Some exhaust gas species, particularly residual (active) radicals (such as $\mathrm{H}, \mathrm{OH}, \mathrm{HO}_{2}$ ), may influence the production and destruction reactions of some radicals. Also, water vapour as an effective third body may affect reactions where a third body plays an important role, such as in termination reactions.

The cumulative influence of the IEGR chemical effect on ignition timing is investigated by fixing the temperature of the resulting charge mixture (air/fuel/IEGR) while varying the IEGR percentage. In that way the thermal effect of IEGR is constant and only the chemical effect will be assessed.

Figure 10 shows the IEGR chemical effect on the ignition timing for $n$-heptane and DME fuels, while Fig. 11 shows those for MB and MF fuels. It can be seen in Fig. 10 that with more IEGR introduction, for both fuels, the start of CF ignition remains almost unchanged, while the MI is significantly delayed. This is due to the fact that the chemical effect of IEGR has little influence on the low-temperature reactions 

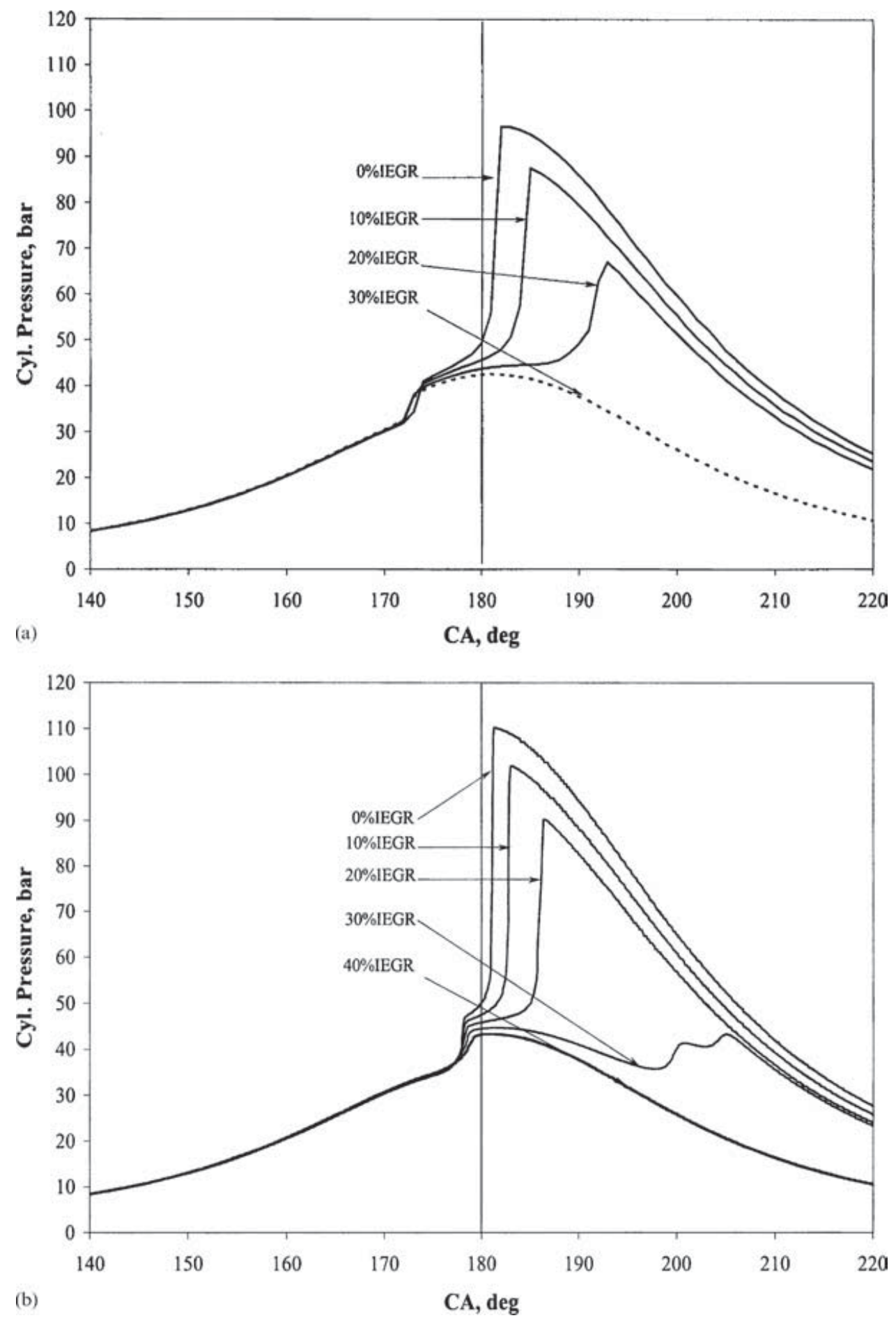

Fig. 10 Cylinder pressure as a function of the IEGR chemical effect for (a) n-heptane and (b) DME fuels.

responsible for CF ignition in $n$-heptane and DME. As discussed in section 6, CF ignition in $n$-heptane is controlled by the $\mathrm{C}_{7} \mathrm{H}_{15}$ radicals, while in DME it is controlled by peroxy radicals, which ultimately leads to a relatively high rate of chain branching from ketohydroperoxide and methoxymethyl $\left(\mathrm{CH}_{3} \mathrm{OCH}_{2}\right)$ decomposition respectively. These chain branching sequences result in an enhanced yield of $\mathrm{OH}$ radicals which start to consume fuel, releasing heat and increasing the temperature of the mixture, and are very little influenced by the IEGR chemical effect (they are almost insensitive to the IEGR chemical effect). Therefore, with increasing IEGR quantities, ignition timing and pressure rise from $\mathrm{CF}$ ignition remains almost unchanged, as can be seen in Fig. 12.

On the other hand, IEGR has a very strong influence on the intermediate-temperature reactions, by reducing 


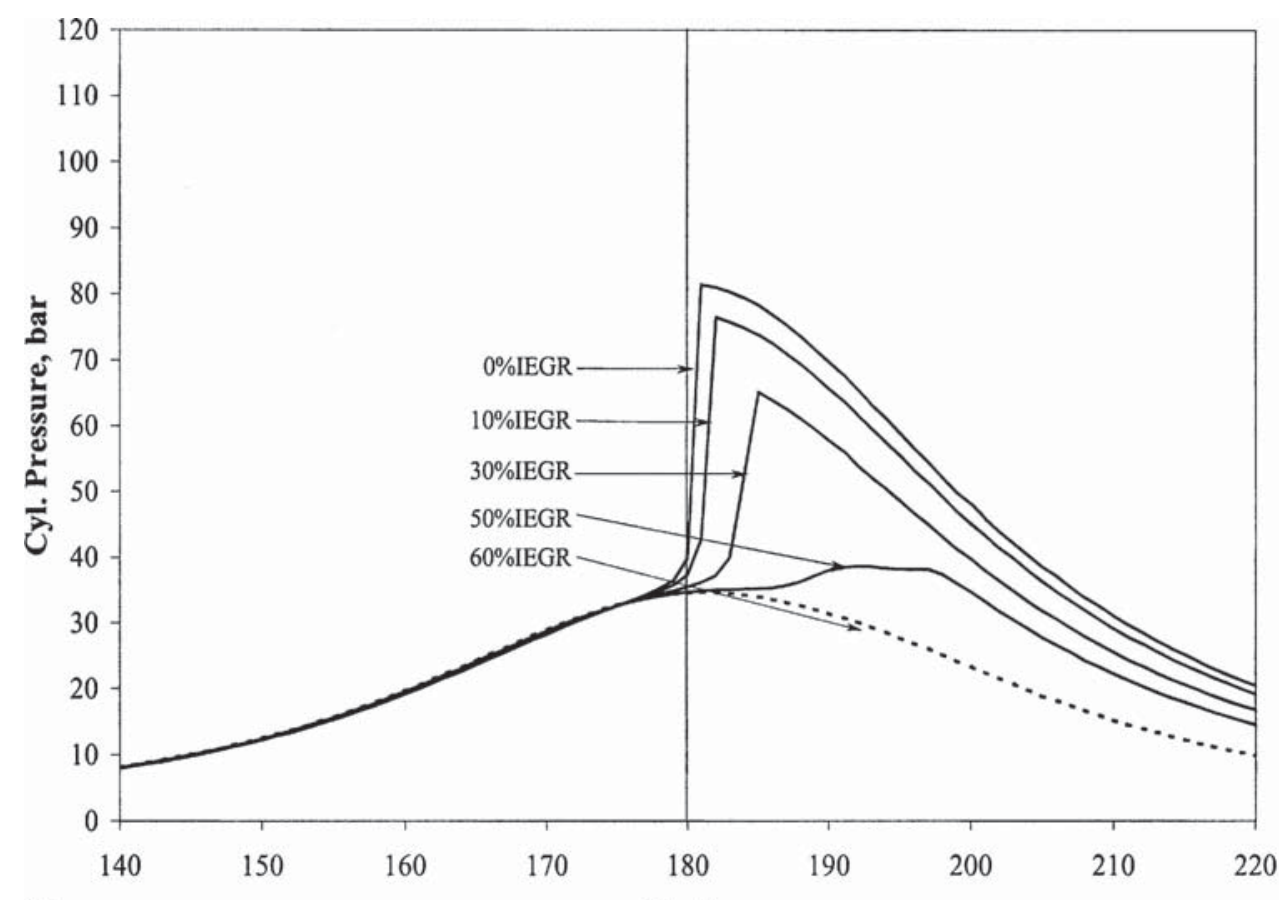

(a)

CA, deg

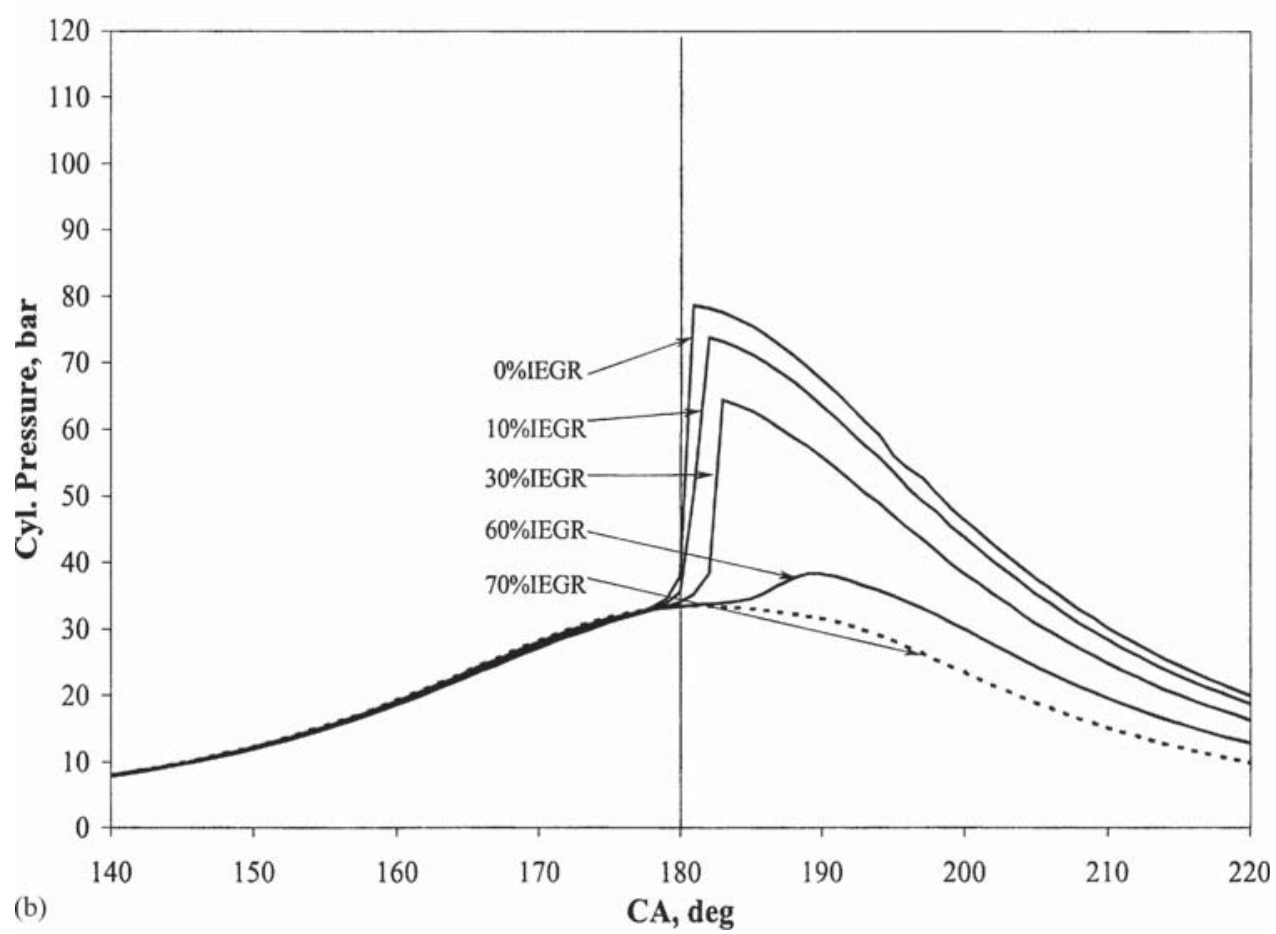

Fig. 11 Cylinder pressure as a function of the IEGR chemical effect for (a) MB and (b) MF fuels.

the accumulation of radical pools and temperature rise in the induction period. This results in the temperature for high-temperature ignition initiation being reached later in the cycle and therefore the $\mathrm{MI}$ is delayed.

n-Heptane exhibits a higher sensitivity to IEGR than DME and thus the lowest tolerance towards IEGR. The ignitability limits, assessed as the quantity of IEGR above which main ignition cannot be initiated, is reached for $n$-heptane at 20 per cent IEGR and for
DME at 30 per cent IEGR. CF ignition for $n$-heptane DME still occurs for higher IEGR amounts, but the strength of CF combustion is not sufficient to overcome the influence of the IEGR chemical effect and thus the main ignition is omitted.

Differences in sensitivity to IEGR between $n$-heptane and DME are due to the nature of the low- and intermediate-temperature chain branching processes that are responsible for CF ignition and the induction period in these fuels, as discussed previously. 


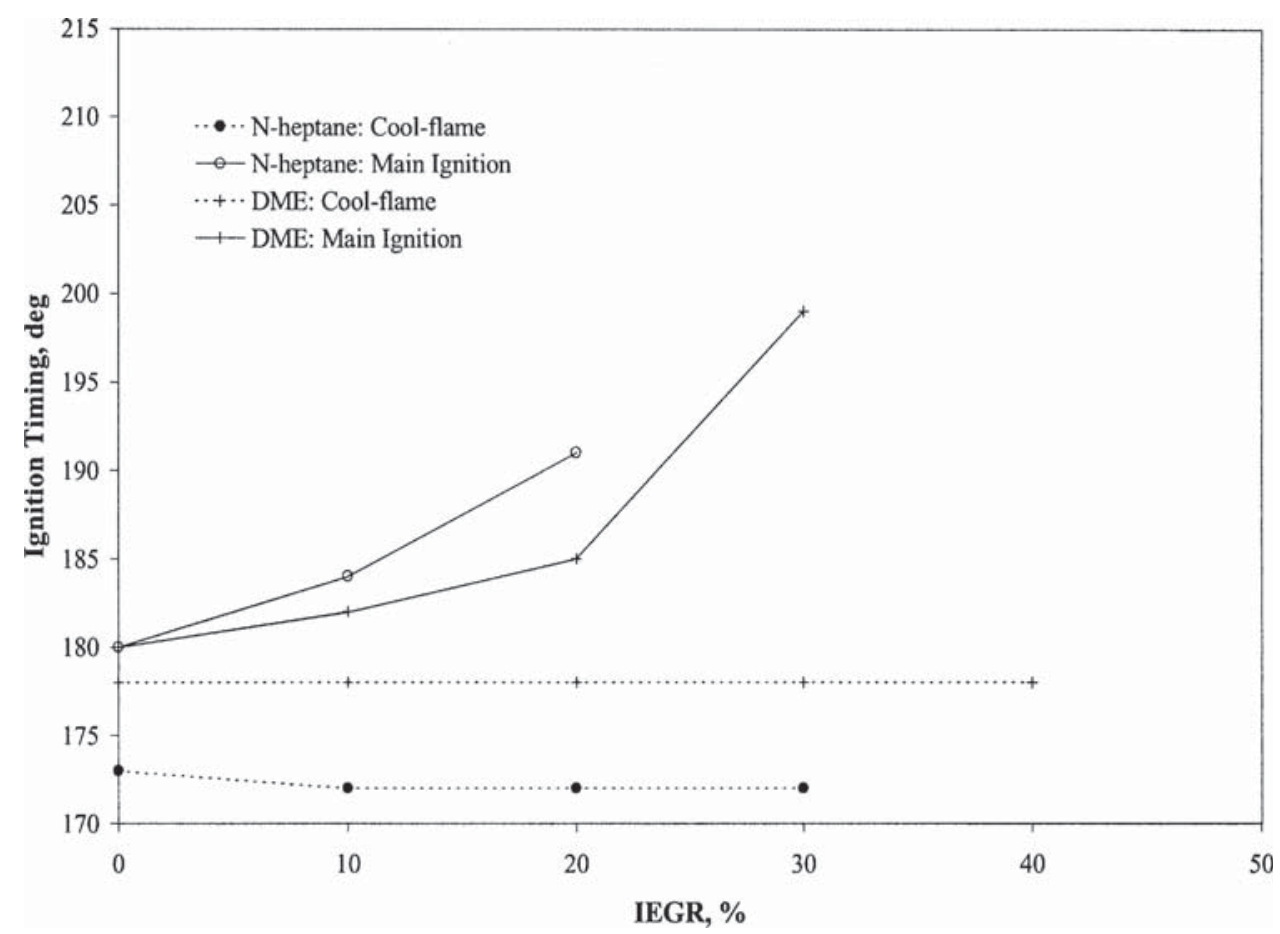

Fig. 12 Chemical effect of IEGR on ignition timing for $n$-heptane and DME fuels. Symbol $(\bigcirc)$ represents n-heptane main ignition, (-) n-heptane cool flame ignition, (+ and solid line) DME main ignition, (+ and dashed line) DME cool flame ignition. The solid line corresponds to main ignition while the dashed line corresponds to cool flame ignition.

It can be seen that the ignition timings for $\mathrm{MB}$ and MF are considerably less affected by the IEGR chemical effect in comparison to the ignition timings of $n$-heptane and DME fuels (refer to Figs 11 and 10).

This behaviour of MB and MF fuel is due to the single-stage ignition process and the faster chemistry leading to the MI. As a consequence of this MB and MF exhibit a higher tolerance to IEGR in comparison to $n$-heptane and DME. It can be seen that the ignitability limit for $\mathrm{MB}$ and MF is achieved at 50 and 60 per cent IEGR respectively, while for $n$-heptane it is 20 per cent IEGR and for DME 30 per cent IEGR (refer to Figs 11 and 10). Even though CF ignition for $n$-heptane and DME fuels still occurs after these values, but strength of CF combustion is not sufficient to overcome the chemical effect of IEGR and thus the MI is omitted.

It is obvious that IEGR influences ignition timing and the further combustion process in an HCCI engine by both temperature and chemical effects. A high IEGR temperature increases the intake mixture temperature in the mixing process inside the cylinder and so sustains the autoignition process without using intake air pre-heating. In addition, IEGR influences the further combustion process by slowing down the combustion rate, hence increasing the heat release duration and reducing the peak cylinder pressure.

As the IEGR has the potential to control the $\mathrm{HCCI}$ combustion, further investigations are required to assess the effect of individual exhaust gas constituents and the effect of possible inhomogenities in the mixing process of exhaust gases and the intake air/fuel mixture.

\section{Conclusions}

The effects of equivalence ratio and engine speed on ignition timing and use of the internal gas recirculation as a potential control strategy in an HCCI engine, fuelled with four different diesel type fuels, $n$-heptane, dimethyl ether, bio-diesel fuels methyl butanoate and methyl formate, were studied. The $n$-heptane and dimethyl ether were characterized with two-stage ignition behaviour, while bio-diesel fuels exhibited single-stage ignition only. These differences have a strong influence on the ignition timing and further combustion event during various engine operating conditions.

Among investigated fuels, DME was the easiest fuel to ignite, followed by $n$-heptane. The methyl butanoate needed a higher temperature for the ignition, while methyl formate demanded the highest inlet temperature.

The results obtained show that there were significant differences in the behaviour of the fuels characterized by two-stage ignition from those having 
only a single stage. The results also show that biodiesel fuels exhibit two significant advantages. The first of these is that bio-diesel fuels allow the use of a very lean mixture $(\phi \leqslant 0.2)$ while keeping the combustion process complete and the second is that variations in ignition timing with changes in the equivalence fuel-air ratio and engine speed are considerably less with bio-diesel fuels than with $n$-heptane and DME. Variations in ignition timing with changes in the equivalence fuel-air ratio for DME are, however, higher than for $n$-heptane but lower for changes in engine speed.

Bio-diesel fuels therefore require less adjustment of engine parameters to maintain optimal ignition timing and low peak cylinder pressure, over the required operating range of an HCCI engine. Internal gas recirculation showed the potential to control ignition timing and further combustion events and to reduce the peak cylinder pressure for all investigated fuels. Using internal gas recirculation, $n$-heptane and DME fuels required a lower amount of trapped exhaust gases to initiate the autoignition process and to sustain complete combustion than bio-diesel fuels.

The ignition timing for $n$-heptane appears to be the most affected by use of IEGR, followed by DME. On the other hand, bio-diesel fuels have exhibited a higher tolerance to the use of IEGR.

One of the possible ways to improve the control of an HCCI engine running on diesel fuel would be to use a mixture of the fuels investigated. The blended fuel should incorporate benefits of lower ignition temperature from DME and higher IEGR tolerance from bio-diesel fuels.

\section{Notation}

$\begin{array}{ll}\mathrm{r} / \mathrm{min} & \text { revolutions per minute }(1 / \mathrm{min}) \\ \varepsilon & \text { compression ratio } \\ \phi & \text { equivalence fuel-air ratio }\end{array}$

\section{Abbreviations}

AVT active valve train

CA crank angle

CF cool flame

DME dimethyl ether

EEGR external exhaust gas recirculation

EGR exhaust gas recirculation

FVVT fully variable valve train

HCCI homogeneous charge compression ignition
IEGR internal exhaust gas recirculation

IVC inlet valve closure

MB methyl butanoate

MF methyl formate

MI main ignition

SI spark ignition

\section{References}

1 Sjöberg, M., Edling, L. O., Eliassen, T., Magnusson, L. and Ångström, H. E. GDI HCCI: effects of injection timing and air swirl on fuel stratification. Combustion and emission formation. SAE Paper 2002-01-0106, 2002.

$2 \mathrm{Au}$, Y. M., Girard, J., Dibble, R., Flowers, D., Aceves, M. S., Martinez-Frias, J., Smith, R. J., Seibel, C. and Maas, U. 1.9-Liter four-cylinder HCCI engine operation with exhaust gas recirculation. SAE Paper 2001-01-1894, 2001.

3 Law, D., Kemp, D., Allen, J., Kirkpartick, G. and Copland, T. Controlled combustion in an IC-engine with a fully variable valve train. SAE Paper 2000-01-0251, 2000.

4 Koopmans, L., Backlund, O. and Denbratt, I. Cycle to cycle variations: their influence on cycle resolved gas temperature and unburned hydrocarbons from a camless gasoline compression ignition engine. SAE Paper 2002-01-0110, 2002.

5 Oakley, A., Zhao, H., Ladommatos, N. and Ma, T. Experimental studies on controlled auto-ignition (CAI) combustion of gasoline in a 4-stroke engine. SAE Paper 2001-01-1030.

6 Ishibashi, Y., Isomura, S., Kudo, O. and Tsushima, Y. Improving the exhaust emissions of two-stroke engines by applying the activated radical combustion. SAE Paper 960742, 1996.

7 Kimura, S., Aoki, O., Ogawa, H., Muranaka, S. and Enomoto, Y. New combustion concept for ultra-clean and high-efficiency small DI diesel engines. SAE Paper 1999-01-3681, 1999.

8 Milovanovic, N. and Chen, R. A review of experimental and simulation studies on controlled auto-ignition combustion. SAE Paper 2001-01-1890, 2001.

9 Golovitchev, V. I., Nordin, N. and Chomiak, J. Neat dimethyl ether: is it really diesel fuel or promise? SAE Paper 982537, 1998.

10 Golovitchev, V. I., Nordin, N., Chomiak, J., Nishida, K. and Wakai, K. Evaluation of ignition quality of DME at diesel engine conditions. In Proceedings of the 4th International Conference on Internal Combustion Engines, Capri, Italy, 1999.

11 Grabovski, M. S. and McCormick, R. L. Prog. Energy Combust. Sci., 1998, 24, 125-164.

12 Fisher, E. M., Curran, H. J., Pittz, W. and Westbrook, C. K. Detailed chemical kinetic mechanisms for combustion of oxygenated fuels. In Proceedings of the 28th Combustion Symposium, Edinburgh, Scotland, July 2000.

13 Kee, R. J., Rupley, F. M., Meeks, E. and Miller, J. A. CHEMKIN III: a Fortran chemical kinetics package for the analysis of gas-phase chemical and plasma kinetics. Report SAND96-8216, Sandia National Laboratories, Livermore, California, 1996. 
14 Heywood, J. B. Internal Combustion Engine Fundamentals, 1988 (McGraw-Hill, Maidenhead).

15 Curran, H. J., Gaffuri, P., Pitz, W. J. and Westbrook, C. K. A comprehensive modelling study of $n$-heptane oxidation. Combust. Flame, 1998, 114, 149-177.

16 Curran, H. J., Gaffuri, P., Pitz, W. J. and Westbrook, C. K. A comprehensive modelling study of iso-octane oxidation. Combust. Flame, 2002, 129, 253-280.

17 Curran, H. J., Pitz, W. J., Westbrook, K. C., Hisham, M. W. M. and Walker, R. W. An intermediate temperature modelling study of the combustion of neopentane. In Proceedings of the 26th Combustion Symposium, Naples, Italy, 1996, pp. 641-649.

18 Curran, H. J., Pitz, W. J., Westbrook, K. C., Callanah, C. V. and Dryer, F. L. Oxidation of automotive primary reference fuels at elevated pressures. In Proceedings of the 27th Combustion Symposium, Colorado, 1998, pp. 379-387.

19 Allen, J. and Law, D. Variable valve actuated controlled auto-ignition: speed loads maps and strategic regimes of operation. SAE Paper 2002-01-0422, 2002.

20 Chen, R., Milovanovic, N., Turner, J. and Blundell, D. Thermal effect of internal gas recirculation on controlled auto ignition. SAE Paper 2003-01-0750, 2003.

21 Turanyi, T., Zsely, G. I. and Frouzakis, C. KINALCCHEMKIN based program for kinetic analysis, 2001; http:/ / www.chem.leeds.ac.uk/Combustion/ Combustion.html or http:/ / garfield.chem.elte.hu/ Combustion/Combustion.html.

22 Aceves, S. M., Smith, R., Westbrook, C. K. and Pitz, W. J. Compression ratio effect on methane HCCI combustion. Trans. ASME., J. Eng. for Gas Turbines and Power, July 1999, 121, 569-574.

23 Aceves, S. M., Flowers, D. L., Westbrook, C., Smith, R., Pitz, W., Dibble, W. R., Christensen, M. and Johansson, R. A multi-zone model for prediction of HCCI combustion and emission. SAE Paper 2000-01-0327, 2000.

24 Cox, A., Griffiths, J. F., Mohamed, C., Curran, H. J., Pitz, W. J. and Westbrook, K. C. Extents of alkane combustion during rapid compression leading to a single and two-stage ignition. In Proceedings of the 26th Combustion Symposium, Naples, Italy, 1996, pp. 2685-2692.
25 Westbrook, C. Chemical kinetics of hydrocarbon ignition in practical combustion systems. In Proceedings of the 28th Combustion Symposium, Plenary Lecture, Edinburgh, Scotland, July 2000.

26 Chevalier, C., Pitz, W. J., Warnatz, J., Westbrook, K. C. and Melenk, H. Hydrocarbon ignition: automatic generation of reaction mechanisms and applications to modelling of engine knock. In Proceedings of the 24th Combustion Symposium, Sydney, Australia, 1992, pp. 93-101.

27 Glassman, I. Combustion, 1st edition, 1977 (Academic Press, New York).

28 Iida, N. and Igarashi, T. Auto-ignition and combustion of $n$-butane and DME/air mixtures in a homogeneous charge compression ignition engine. SAE Paper 2000-01-1832, 2000.

29 Aceves, S. M., Flowers, D. L., Martinez-Frias, J., Smith, R., Westbrook, C., Pitz, W., Dibble, W. R., Wright, F. J., Akinyemi, W. C. and Hessel, R. P. A sequential fluid-mechanic chemical-kinematic model of propane HCCI combustion. SAE Paper 2000-01-1027, 2000.

30 Aceves, S. M., Martinez-Frias, J., Flowers, D. L., Smith, R., Dibble, W. R., Wright, F. I. and Hessel, R. P. A decoupled model of detailed fluid mechanics followed by detailed chemical kinetics for prediction of iso-octane HCCI combustion. SAE Paper 2001-01-3612, 2001.

31 Chen, R. and Milovanovic, N. A computational study into the effect of exhaust gas recycling on homogeneous charge compression ignition combustion in internal combustion engine fuelled with methane. Int. J. Thermal Sci., 2002, 41, 805-813.

32 Milovanovic, N., Chen, R., Law, D. and Turner, J. A computational study on the effect on auto-ignition timing of HCCI engine fuelled with $n$-heptane, isooctane, ethanol and methane. In Proceedings of the 17th Internal Combustion Engine Symposium, Tokyo, Japan, October 2002, Paper 20026074, pp. 351-354 (ISAE).

$33 \mathrm{Dec}, \mathrm{J}$. A computational study of the effect of low fuel loading and EGR on heat release rates and combustion limits in HCCI engines. SAE Paper 2002-01-1309, 2002.

34 Zhao, H., Peng, Z., Williams, J. and Ladommatos, N. Understanding the effects of recycled-burnt gases on the controlled auto-ignition (CAI) combustion in fourstroke gasoline engines. SAE Paper 2001-01-3607, 2001. 